Polymer Journal, Vol. 38, No. 10, pp. 1005-1022 (2006)

(C) 2006 The Society of Polymer Science, Japan

REVIEW ARTICLES

\title{
Morphology Control of Aromatic Polymers in Concert with Polymerization
}

\author{
Kunio KIMURA, ${ }^{\dagger}$ Shin-ichiro KoHAma, and Shinichi YAMAZAKI \\ Graduate School of Environmental Science, Okayama University, \\ 3-1-1 Tsushima-naka, Okayama 700-8530, Japan
}

(Received July 25, 2006; Accepted August 1, 2006; Published September 15, 2006)

\begin{abstract}
Morphology control methods of aromatic polymers in concert with polymerization reaction are described in this review. Many attractive methods have been developed including reaction-induced phase separation of oligomers, epitaxial polymerization, shear-induced chain orientation during gelation, template-based polymerization, suspension polycondensation, solid-state polycondensation and liquid-liquid interfacial precipitation and so on. Among them, the reaction-induced phase separation of oligomers, in which there are two modes of crystallization and liquidliquid phase separation, possess practically high potentiality to create novel polymer materials since it can control not only the morphology but also the molecular chain orientation. Ultimate goal is the embodiment of the nature system in a flask, that is, the control of the materials from primary structures to super structures. The morphology control methods by using polymerization reaction afford the valuable methodology for the three-dimensional structure architecture. [doi:10.1295/polymj.PJ2006083]

KEY WORDS Morphology / Phase Separation / Oligomer / Whisker / Microsphere / Epitaxy / Aromatic Polymer /
\end{abstract}

Morphology of polymer materials is of great importance as well as the molecular chain orientation for the creation of new functional and high-performance materials possessing essential properties predicted from their molecular structures. From the both aspects of molecular chain orientation and morphology, one of the ideal materials is a needle-like single crystal of extended molecular chains called polymer whisker. Especially, wide variety of polymeric nanomaterials is required for supporting nanotechnology and the more precise controls are rapidly necessitated in these days. Hence, the demand for the morphology control method increases significantly. Usually, extended molecular chain crystals are difficult to obtain by conventional processing methods and the special processing techniques have been developed thus far. ${ }^{1}$ There exists another stream for the development of extended molecular chain crystals by means of crystallization during polymerization. The needle-like crystals of both flexible and rigid polymers have been obtained by the solid-state polymerization of the monomers and the polymerization in the solution. Examples of the former polymerization have included oxacyclobutanes such as 1,3,5-trioxane, ${ }^{2,3}$ diolefins undergoing four-center type photopolymerization ${ }^{4,5}$ and monomers with conjugated triple bonds such as substituted diacetylenes. ${ }^{6,7}$ On the other hand, the first polymer whisker was obtained by the cationic ring-opening polymerization of 1,3,5-trioxane.$^{8-10}$ The obtained polyoxymethylene whiskers were $1-2 \mu \mathrm{m}$ in width and $10-50 \mu \mathrm{m}$ in length. The molecular chains aligned along the long axis of the whisker. They were brought into practical uses with its unique morphology and good mechanical properties. ${ }^{11,12}$ However, the polyoxymethylene whisker has a melting temperature at $180^{\circ} \mathrm{C}$ and the low melting temperature limits the broader commercial utilization as high-performance materials.

Aromatic polymers are characterized by their excellent properties such as mechanical strength, thermal stability, chemical resistance, and they have been attracted as high performance polymer materials. ${ }^{13}$ Recently, they have also been receiving attention as functional polymers due to their good optical and electrical property. Numerous types of rigid-rod aromatic polymers have been synthesized to create new materials. The processing of these materials is generally more difficult than that of conventional flexible chain polymers owing to their insolubility and infusibility caused by the strong enthalpic interactions and the minimal increase in conformational entropy associated with their dissolution or melting. In order to overcome this trade-off relationship between the intractability and the excellent properties of aromatic polymers, many studies have been launched to develop the morphology control methods so far. The proce-

${ }^{\dagger}$ To whom correspondence should be addressed (Tel\&Fax: +81-86-251-8902, E-mail: polykim@cc.okayama-u.ac.jp). 


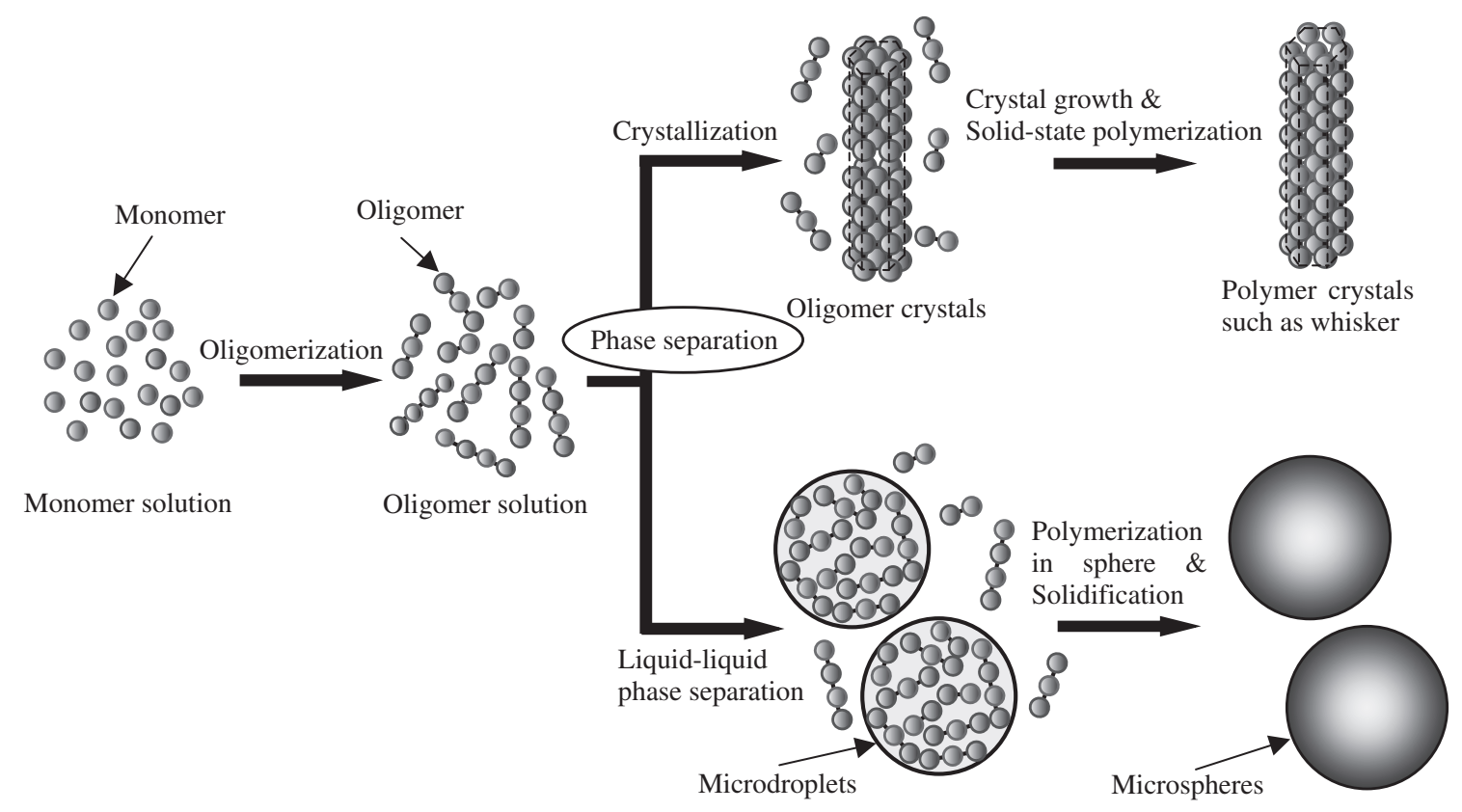

Figure 1. Schematic drawing of morphology control of aromatic polymers by using reaction-induced phase separation of oligomers during solution polymerization.

dures are mainly divided into three categories. The first is the morphology control by special processing techniques such as electro-spinning, liquid crystalline solution spinning and so on, the second is that by using the self-assembling of polymers, and the third is that by using the polymerization. Among them, the latter two are built-up type control methods and various morphologies have been created so far. The morphology control during polymerization is very useful and its potentiality seems higher than others because this method is not limited at all by the intractability of the polymers.

As mentioned, there are numerous studies of morphology control for various polymers. Among them, this article focuses on aromatic polymers prepared by step growth polymerization and reviews the progress in the morphology control in concert with polymerization reaction.

\section{REACTION-INDUCED PHASE SEPARATION OF OLIGOMERS DURING SOLUTION POLYMERIZATION}

The morphology control by using reaction-induced phase separation of oligomers is shown in Figure 1. This methodology is similar to that in nature. The self-assembling process is combined with the polymerization process by using phase separation of oligomers, and both processes occur simultaneously and concertedly. It is like building blocks of oligomers to form the morphology with the polymerization. The polymerization is necessarily carried out in poor solvents to induce the phase separation of oligomers.
Reaction-induced phase separation of oligomers in poor solvents is describable on the analogous concentration-temperature phase diagram to that of the partially miscible polymer-solvent system. ${ }^{14,15}$ The phase separation curve in the repulsive system, where there is no attractive interaction between oligomers and solvents, can be written as the combination of the freezing point curve of the oligomers and the upper critical solution temperature type consolution curve. Aromatic polymers discussed here are usually prepared by the step-growth polymerization represented by polycondensation reaction. Oligomers are formed by the polymerization reaction, and the molecular weight of oligomers increases stepwise in the solution. When the molecular weight of oligomers exceeds a critical value, the oligomers are phase-separated from the supersaturation state. If the supersaturated oligomers are across the freezing point curve, they are precipitated by the crystallization to form the crystals, and the polymer crystals are finally formed by the post polymerization in the crystals. On the other hand, if across the consolution curve, the oligomers are precipitated through liquid-liquid phase separation and droplets of dense phase are generated in dilute phase. Finally, polymer particles are formed due to the solidification of the fine droplets caused by the further polymerization in them. Miscibility between the oligomers and the solvents is a variable parameter to control the morphology.

\section{Reaction-induced Crystallization}

Whiskers and fibrous crystals of numerous types of aromatic polymers have been prepared by this method 


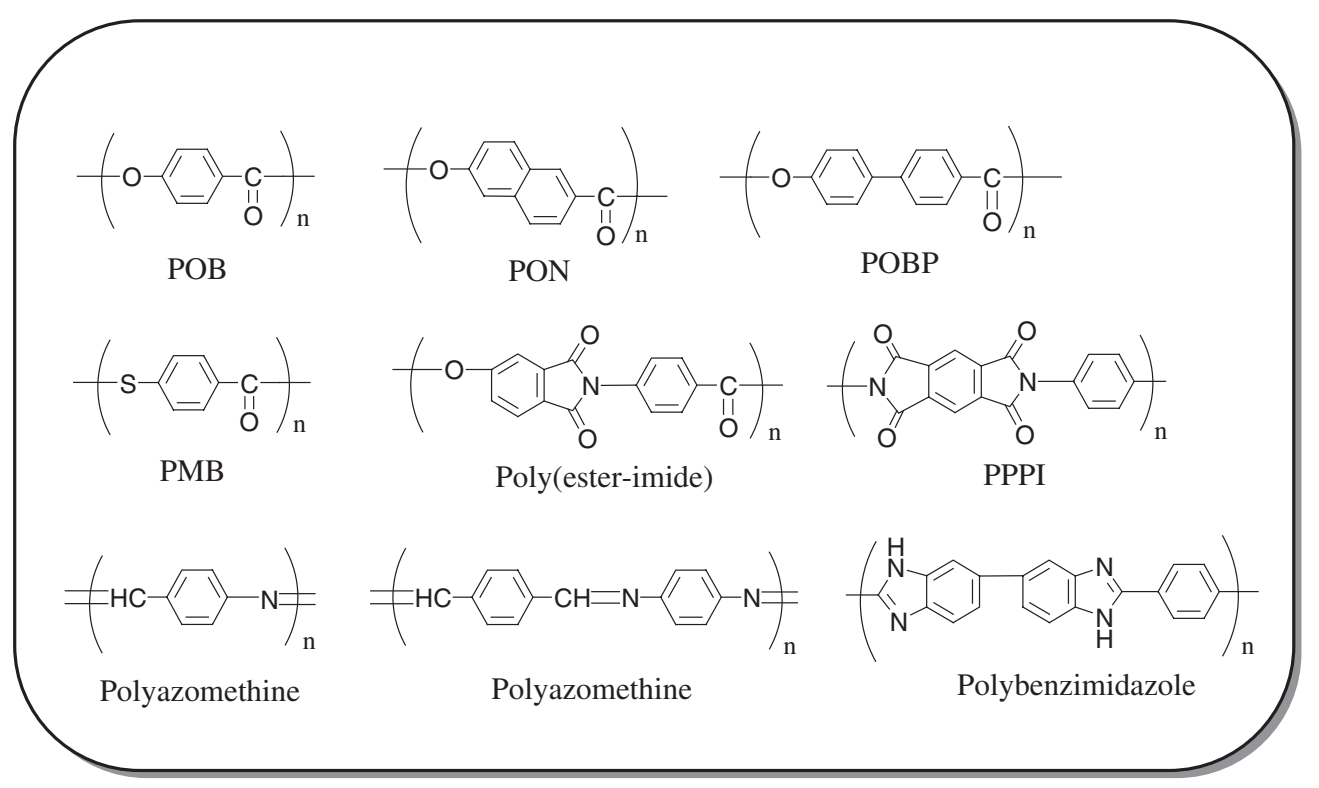

Scheme 1. Aromatic polymers giving whiskers and fibrous crystals by reaction-induced crystallization of oligomers.

as shown in Scheme 1. The first synthesis of aromatic polymers by the reaction-induced crystallization was developed for the synthesis of wholly aromatic polyesters. ${ }^{16,17}$ Poly ( $p$-oxybenzoyl) (POB), which is an intractable polymer, had been predicted to possess outstanding properties and expected as a hopeful candidate for high-performance materials. POB is usually synthesized by the polycondensation of $p$-acetoxybenzoic acid (ABA) over $300^{\circ} \mathrm{C}$ with elimination by-produced acetic acid. However, it was very difficult to obtain high molecular weight POB by the melt polymerization owing to the higher melting temperature than its decomposition temperature, and hence POB was not used as materials. The polymerization of ABA was performed in an inert aromatic heat exchange media Therminol-66 (a mixture of isomers of cyclohexylbiphenyls and dicyclohexylbiphenyls) at $320^{\circ} \mathrm{C}$ with no catalyst and high molecular weight POB was successfully obtained as precipitates. The obtained precipitates were very uniform slab-like crystals and they were $c a .1 \mu \mathrm{m}$ in thickness and $c a$. 3-4 $\mu \mathrm{m}$ in width with a clearly defined lamellar structure along the thickness. These crystals possessed extremely high crystallinity and the molecular chains extended the entire thickness of the lamella. This study aimed to prepare high molecular weight POB, but the result gave a strong impact for the morphology control. The role of the monomers in the preparation of POB single crystal was also investigated by using ABA, phenyl $p$-hydroxybenzoate, ${ }^{18} p$-(pivaloyloxy)benzoic acid and $p$-(trimethylsiloxy)benzoyl chloride. ${ }^{19}$ The polymerization of $\mathrm{ABA}$ afforded the single crystals and morphological features could be observed during the conversion of oligomers to polymers, enabling the determination of mechanisms likely to con- trol chain growth for different regimes of polymerization kinetics. POB whiskers were successfully prepared by the polymerization of $\mathrm{ABA}$ in liquid paraffin at very low concentration with no stirring. ${ }^{20-26}$ Desirable polymerization temperature and the concentration were $300-330^{\circ} \mathrm{C}$ and $1 \%$, respectively. ABA was not soluble in liquid paraffin at room temperature, but it became soluble while heating at $330^{\circ} \mathrm{C}$. The solution became turbid after several minutes at $330^{\circ} \mathrm{C}$ due to the precipitation of oligomers and the whiskers were finally obtained after $6 \mathrm{~h}$. The obtained POB whiskers were $30-70 \mu \mathrm{m}$ in length and $1 \mu \mathrm{m}$ in diameter, as shown in Figures $2 a$ and $2 b$. The both tips of the whiskers are sharp and they show very symmetrical shape. The cross section is hexagonal. The morphology of the POB crystals highly depended on the polymerization solvent as also shown in Figures 2c2e. Fibrillar crystals were formed in benzophenone, fine slab-like powders were obtained in 4-chlorobenzophenone. Spherulitic aggregates were observed by the polymerization in diphenyl sulfone. The whiskers obtained in liquid paraffin gave sharp peaks in the $\mathrm{X}$-ray diffraction patterns and no diffuse hallo attributed to amorphous region. The POB whiskers possessed quite high crystallinity and the observed density $\left(1.50-1.51 \mathrm{~g} \mathrm{~cm}^{-3}\right)$ of the whiskers was close to the density $\left(1.52 \mathrm{~g} \mathrm{~cm}^{-3}\right)$ calculated from the crystal data. The electron diffraction pattern obtained from one single whisker is shown in Figure 3. The diffraction pattern is not a true fiber pattern of cylindrical symmetry and many sharp spots are observed from lower to higher diffractions. The meridian of this diffraction pattern corresponds to the long axis of the whisker, indicating the extended polymer molecules align along the whisker axis. The fiber identity period is 

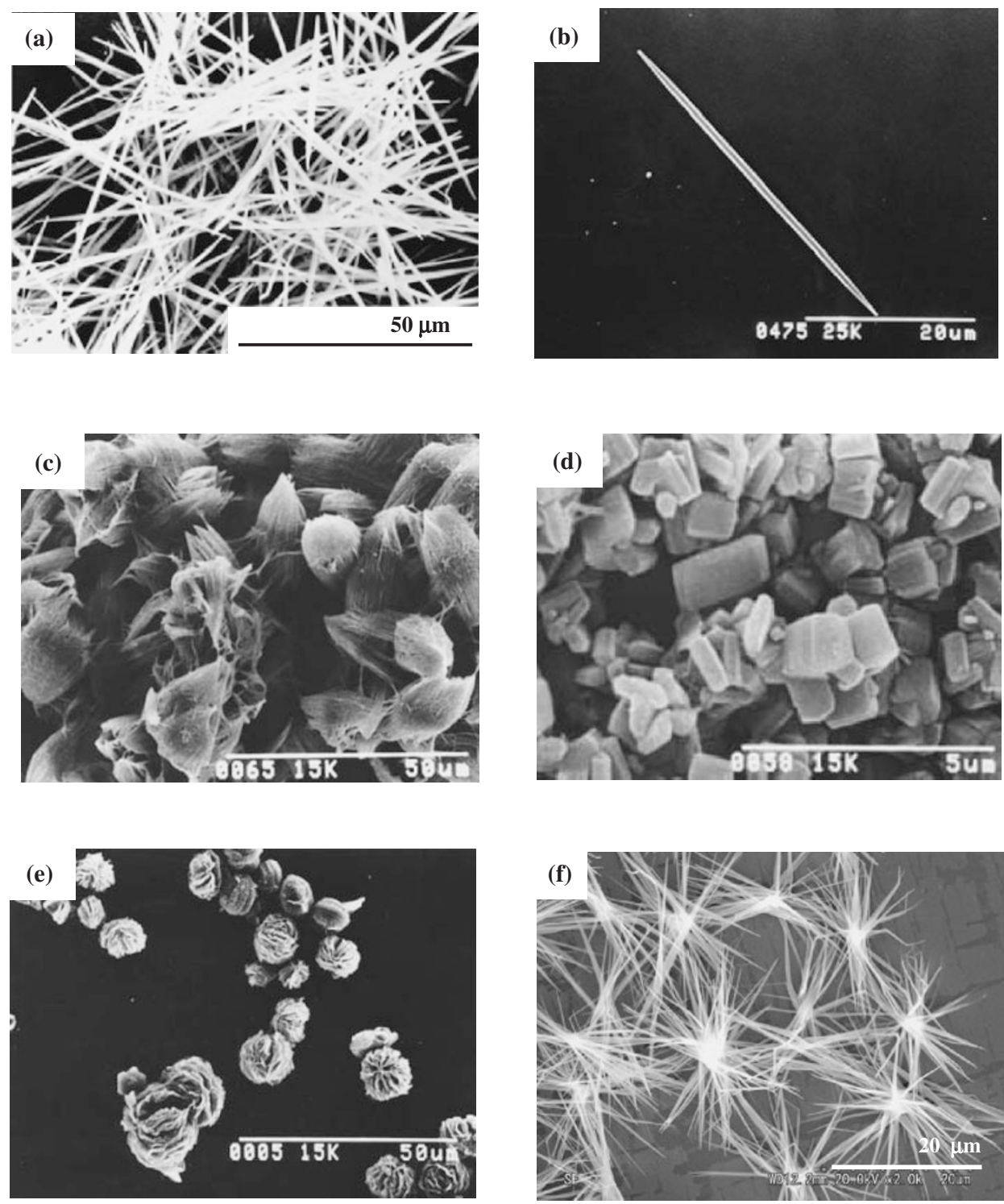

Figure 2. POB crystals prepared in (a), (b) liquid paraffin, (c) benzophenone, (d) 4-chlorobenzophenone, (e) diphenyl sulfone and (d) POB nanowhiskers.

$1.254 \mathrm{~nm}$, corresponding to 2 repeating units. It has been well known that POB crystals exhibit a crystalcrystal transition at $320-350{ }^{\circ} \mathrm{C}$, which is due to the order-disorder transition between two orthorhombic phases. ${ }^{27-31}$ DSC measurement of the POB whiskers showed a sharp endothermic peak at approximately $370^{\circ} \mathrm{C}$ and higher transition temperature revealed close packing of the chains in the whisker. The formation mechanism of the POB whiskers prepared in liquid paraffin was discussed with the morphological observations. As shown in Figure 4, the hexagonal lamellae are firstly formed at the early stage in the polymerization. The trace of the screw dislocation was observed on the lamellae. Then the length and the width of the whiskers increase with time from the center to the both tips. The needle crystals in the very early stage of polymerization consist of the stacks of oligomer lamellae, of which the thickness of the lamellae is $c a .5 .0 \mathrm{~nm}$. The stacking structures disappear at the middle of the polymerization due to the polymerization of oligomers between lamellae and the whiskers having very smooth surface are eventually formed. The oligomers dissolved in the solution were collected and analyzed by HPLC. The oligomers left in the solution were the mixture of ABA to heptamers, and higher oligomers than octamer were precipitated via crystallization to form the crystals. The length of the octamer is in good agreement with the lamellae thickness. The change on molecular weight was followed during POB whisker formation with the yield. The number average degree of polymerization (DPn) of the whiskers was estimated by the end-group analysis. The DPn and the yield of the whiskers are plotted with the time as shown in Figure 5. The DPn of whiskers obtained within 3 min after crystal precipitation increases from 8 to 
48. Furthermore, transesterification reaction in the interlamellar regions starts as soon as crystal precipitation. The DPn increases linearly after the yield is leveled off due to the effective solid-state polymerization. Reorganization into extended chain crystals occurs, accompanied by the increase of DPn. The DPn of the eventual whiskers reaches 1860 after $25 \mathrm{~h}$ and the average molecular length exceeds $1 \mu \mathrm{m}$. The

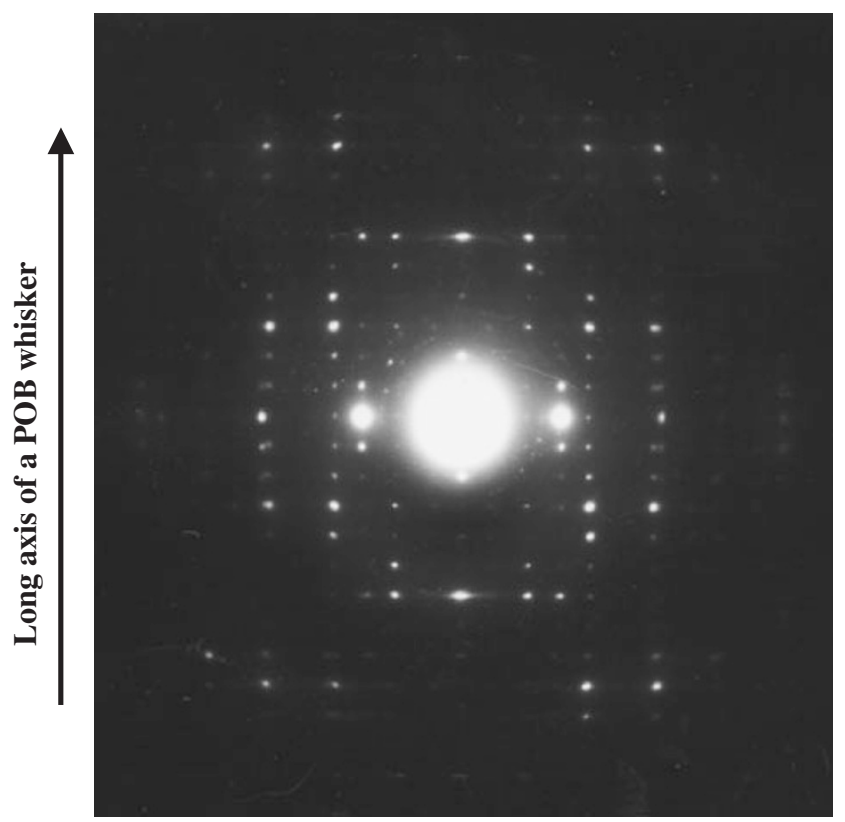

Figure 3. Electron diffraction pattern obtained from one single $\mathrm{POB}$ whisker.

(a)
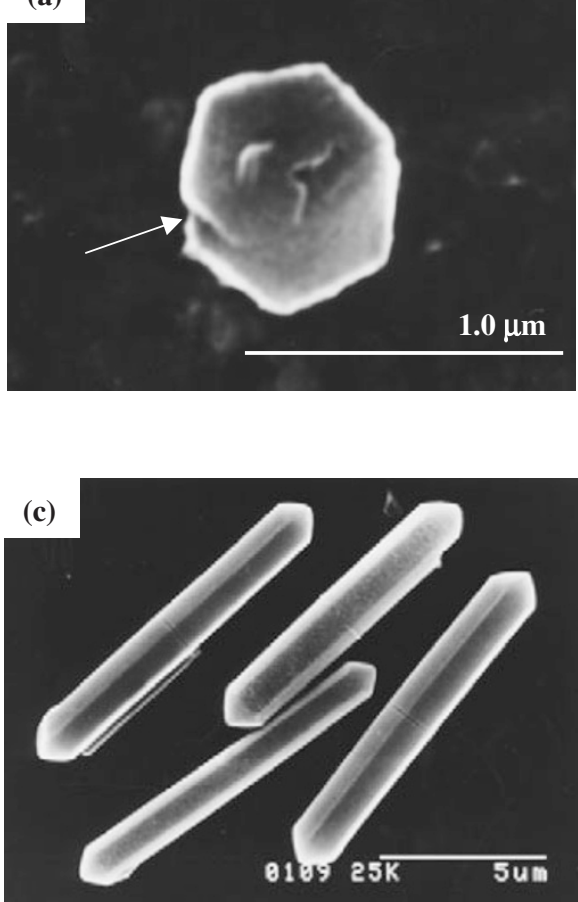

formation of such high-molecular weight polymers in the solid-state polymerization is caused by the closely packed structure of the end groups. The formation mechanism of the whisker had proposed to contain the following steps: The oligomers of low DPn polymerized in solution are precipitated in the form of lamella and the lamellae pile up along the long axis of the needle crystals with a spiral growth caused by the screw dislocation. DPn increases by the transesterification in the interlamellar regions with reorganizing the molecular chain orientation and the chain packing. In an aromatic solvent like Marlotherm-S (a mixture of isomeric dibenzylbenzenes, Huls AG Co. Ltd.),

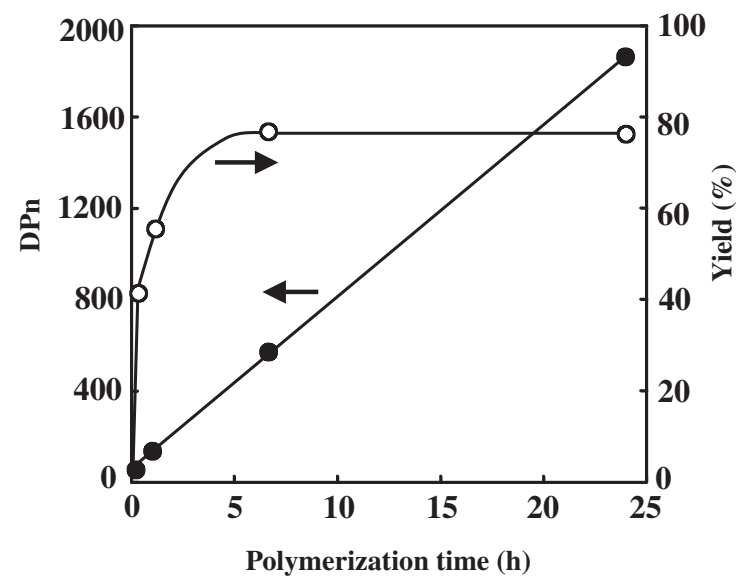

Figure 5. Plots of yield and DPn of POB whiskers prepared in liquid paraffin at $330^{\circ} \mathrm{C}$ as a function of polymerization time.
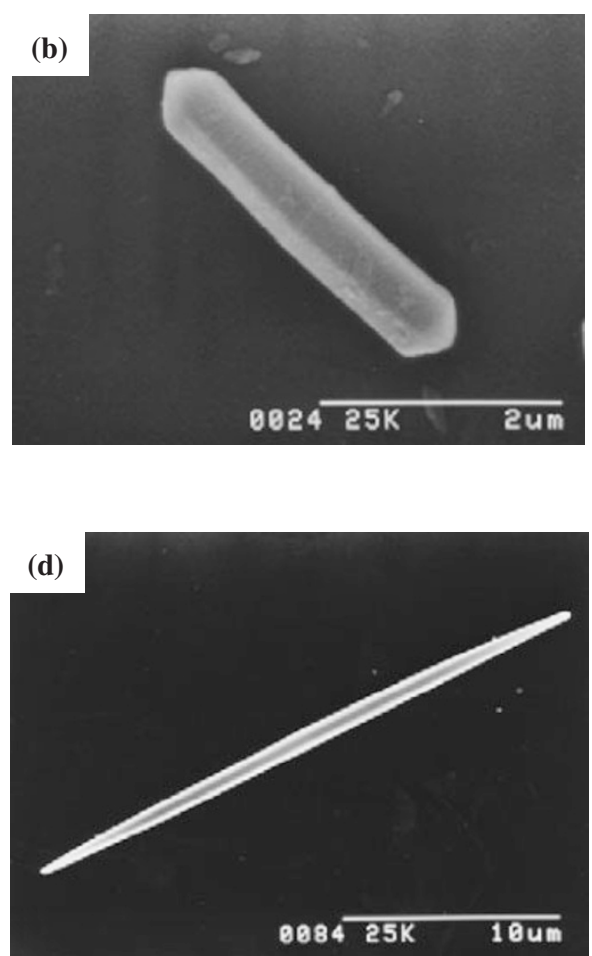

Figure 4. POB crystals prepared in liquid paraffin at $330^{\circ} \mathrm{C}$ for (a) $10 \mathrm{~s}$, (b) $3 \mathrm{~min}$, (c) $19 \mathrm{~min}$ and (d) $30 \mathrm{~min}$. Only a POB crystal prepared for $3 \mathrm{~min}$ was treated with aqueous $\mathrm{KOH}$ solution to remove oligomers adhered on crystal surface. 
the $\mathrm{POB}$ whiskers were also prepared from $\mathrm{ABA}^{32-34}$ and trimethylsilyl $p$-(trimethylsilyloxy)benzoate ${ }^{35}$ under the similar polymerization conditions. Fibrous whiskers with lengths $\geq 100 \mu \mathrm{m}$ and axial ratio $>50$ were only obtained at low monomer concentrations. In this polymerization, the lamellae stacking structure was not observed and therefore another formation mechanism might be existed like the lateral growth without screw dislocation.

Size control methods were developed on the basis of the formation mechanism. The formation mechanism of the whiskers is the nucleation and growth mechanism, and hence there are two control methods to lengthen the whisker. One is the control of the nucleation process and another is the control of the growth process. The former method is to control the number of the nuclei and their radius. It is well known that critical radius of nucleus and nucleation rate depend on the degree of supersaturation. ${ }^{36,37}$ When the degree of supersaturation increases, difference in chemical potentials $(\Delta \mu)$ becomes larger, which is a driving force for nucleation. This large $\Delta \mu$ leads to small critical radius of nucleus and large nucleation rate, resulting in that the much more nuclei having smaller radius are formed. There seems to exist several parameters to influence the degree of supersaturation such as miscibility between oligomers and solvents, formation rate of oligomers, concentration, temperature and so on. Polymerizations in lower miscible solvent such as linear paraffin and fluorinated polyether afford the shorter and thinner POB whiskers in the range of $8-78 \mu \mathrm{m}$ of the length and $0.4-1.5 \mu \mathrm{m}$ of the width. ${ }^{38-41}$ With respect to the control of the growth process, oligomers were added into the polymerization solution to keep the concentration of oligomers constant for the preparation of longer POB whiskers. When oligomers were added to compensate the consumed oligomers during the steady growth period, the length increased continuously corresponding to the addition of oligomers. Recently, nanowhiskers were prepared by the polymerization of ABA in liquid paraffin applying self-seeding method. ${ }^{42}$ The width of the POB whiskers was susceptible to polymerization temperature affecting the degree of the supersaturation and it was efficiently controlled by a change in temperature during the polymerization. Increase in polymerization temperature just after nucleation (Han) reduced the degree of super saturation of oligomers $(\sigma)$ resulting in the depression of the width increase by the crystallization of oligomers on side surface of the whiskers. Temperature drop just before nucleation (Cbn) enhanced the value of $\sigma$ resulting in the generation of much more nuclei having the smaller width. On the basis of these results, the combination of these two methods Han and Cbn afforded the whiskers having the smallest width, and the POB nanowhiskers, as shown in Figure 2f, were prepared of which the width and the length were $190 \mathrm{~nm}$ and $18.6 \mu \mathrm{m}$, respectively. This is regarded as a new fiber fabrication procedure called non-spinning fiber formation.

The finding of the POB whisker accelerates to apply this procedure to other polymers. The first application was the formation of poly(2-oxy-6-naphthoyl) $(\mathrm{PON}) . \mathrm{PON}$ is also the wholly aromatic intractable polyesters. The synthesis of high molecular weight PON in Therminol-66 was reported ${ }^{43}$ and the uniform slab-like crystals measuring $1 \mu \mathrm{m}$ in thickness and ca. $5-8 \mu \mathrm{m}$ in width were obtained as well as POB. The polymerization of 2-acetoxy-6-naphthoic acid in liquid paraffin at $330{ }^{\circ} \mathrm{C}$ and a concentration of $1 \%$ with no stirring yielded the PON whiskers as shown in Figures $6 \mathrm{a}, 6 \mathrm{~b}$ and $6 \mathrm{~d} .{ }^{20,26,44,45}$ The important factors in controlling PON crystal morphologies during high-temperature solution polymerization are polarity of solvent, concentration of monomer, and stirring. Less-polar solvents, like liquid paraffin or aromatic solvent Therm S 800 (a mixture of triethylbiphenyl, Nippon Steel Chemical Co. Ltd.), a low monomer concentration, and no stirring are desirable for making the uniform PON whiskers. The size of the whisker prepared in liquid paraffin was $7-17 \mu \mathrm{m}$ in length and $0.5-1.0 \mu \mathrm{m}$ in width. Based on its electron diffraction pattern, this PON whisker exhibited a single crystal nature and the polymer chains aligned along the long axis of the whisker. Owing to the close packing of polymer chains in this crystal, the whisker has the highest thermal stability compared with the other fibrillar and slab-like crystals. The formation mechanism of the PON whiskers was also investigated in comparison to that of the POB whiskers and the lamellae stacking structure in the incipient PON whisker was more clearly observed as shown in Figure 6c. The lamellae stacking structure disappeared with polymerization and the whiskers having smooth surface were finally formed as shown in Figure 6d as well as the POB whiskers. The formation of the PON whiskers from the polymerization of trimethylsilyl 6-acetoxy-2-naphthoate and one-pot preparation of the PON whiskers from 6-hydroxy-2-naphthoic acid with acetic anhydride were also examined. ${ }^{46}$ The size control method of the POB whiskers could be used for the PON whiskers. ${ }^{47}$

Poly(4'-oxy-4-biphenylcarbonyl) (POBP) crystals were prepared from 4'-acetoxybiphenyl-4-carboxylic acid (ABPA) by the similar high-temperature solution polycondensation. ${ }^{48}$ When the polymerization was carried out in aromatic solvents, bundle-like aggregates of fibrillar crystals were obtained. Their length and width were $5-10 \mu \mathrm{m}$ and $0.1-0.2 \mu \mathrm{m}$, respec- 

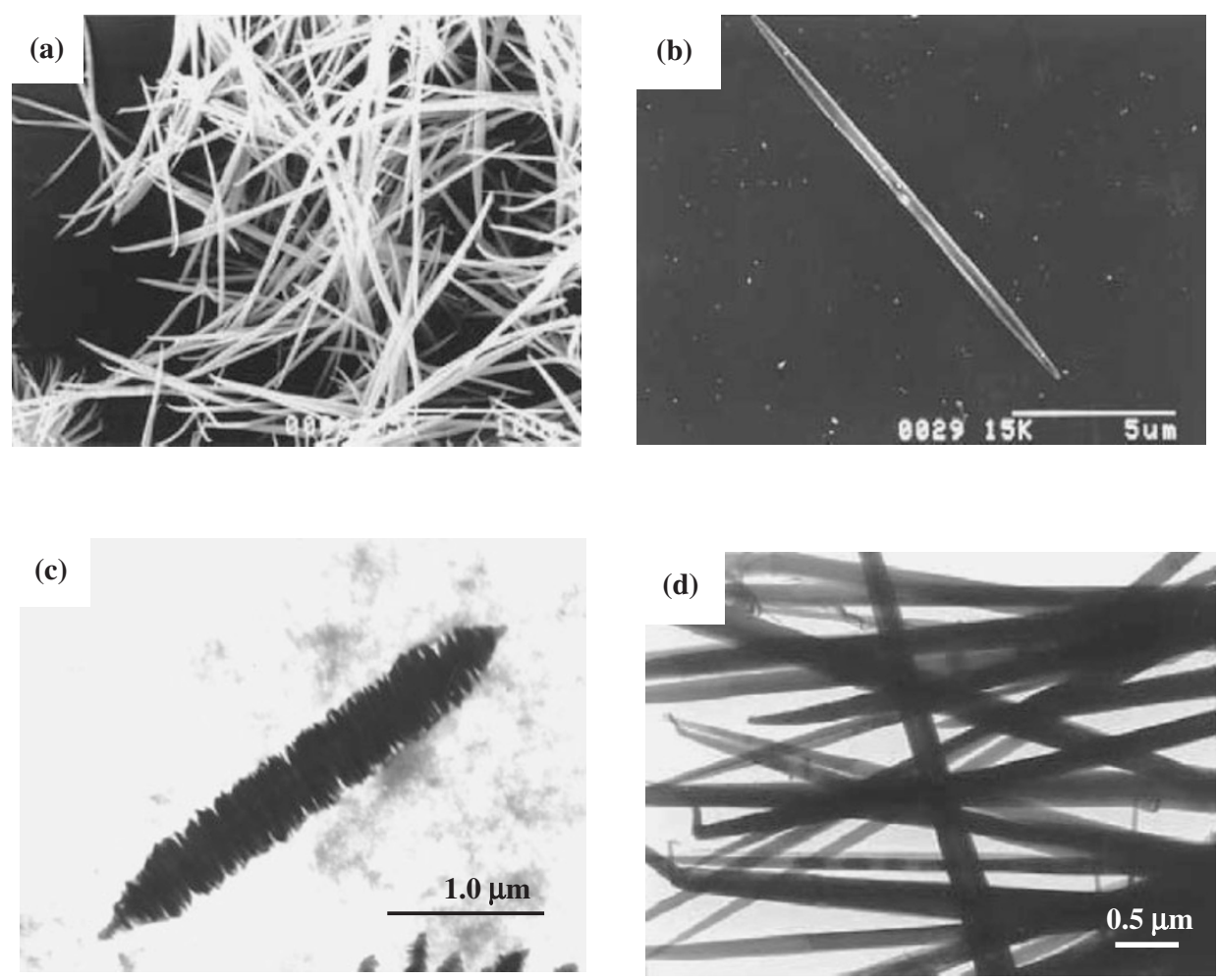

Figure 6. PON whiskers prepared for (a) and (b) $6 \mathrm{~h}$ (SEM). PON incipient crystals prepared for 3 min (c) and PON whiskers prepared for $6 \mathrm{~h}(\mathrm{~d})(\mathrm{TEM})$.
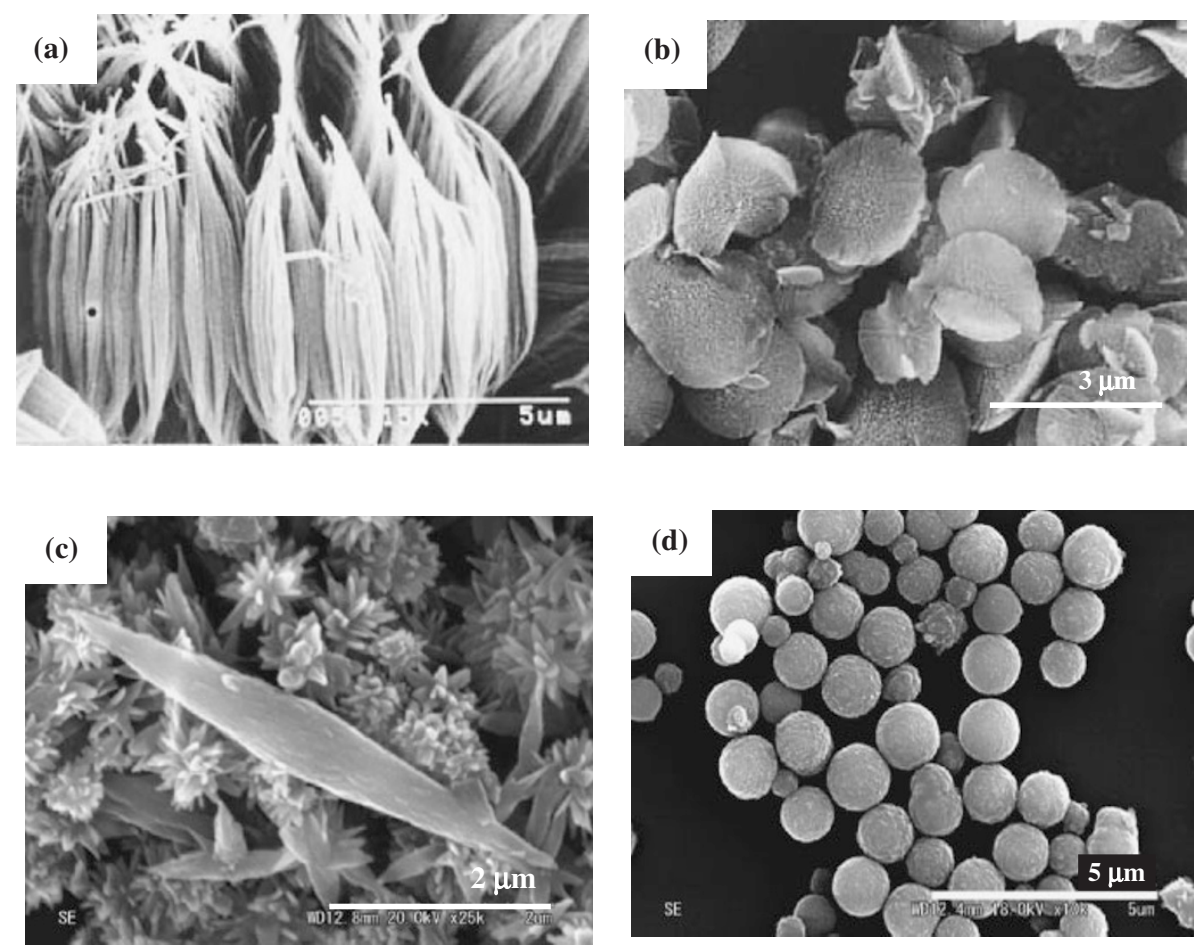

Figure 7. Morphology of (a) POBP bundle-like aggregates of fibrillar crystals prepared for $6 \mathrm{~h}$, (b) POBP lens-like crystals prepared for $2 \mathrm{~h}$, (c) PPPI lozenge-shaped crystals and (d) PPPI microspheres.

tively. These fibrillar crystals were linked laterally to one another at the central part as shown in Figure $7 \mathrm{a}$. The electron diffraction experiments revealed that the polymer chains aligned along the long axis of the fi- brillar crystals. The formation mechanism of the fibrillar crystals was proposed by the observation of the crystal morphology and the polymerization time dependencies of the yield of the crystals, the crystal 
sizes, and the DPn. Incipient crystals obtained after $1 \mathrm{~h}$ showed convex-lens-like shape and the trace of the spiral growth was observed at their thin edges. The crystals obtained after $2 \mathrm{~h}$ showed lens-like shape and they had many protrusions with a width of 0.1$0.2 \mu \mathrm{m}$ on their surfaces as shown in Figure $7 \mathrm{~b}$. This result indicated that the reorganization of crystals was accompanied by an increase of the molecular weight by solid-state polymerization. The formation mechanism of the bundle-like aggregates of fibrillar crystals is fundamentally similar to that in the POB whiskers and the apparent difference in crystal morphology is caused by the reorganization of crystals. Although the polymerization of ABPA at $330^{\circ} \mathrm{C}$ did not give the POBP whiskers, the polymerization in Marlotherm-S at $400^{\circ} \mathrm{C}$ gave the whisker-like crystals, of which the length was up to $10 \mu \mathrm{m}$ and the width was $1-2 \mu \mathrm{m} .{ }^{49}$ The higher polymerization temperature is desirable for the preparation of the POBP whiskers.

AA-BB type aromatic polyesters were examined to prepared the whiskers. Poly ( $p$-phenylene terephthalate) (PPTE) crystals were prepared by high-temperature solution polymerization via three different types of reactions: bimolecular condensation of 1,4-diacetoxybenzene and terephthalic acid, and hydroquinone and diphenyl terephthalate, and self-condensation of $4^{\prime}$-acetoxyphenyl terephthalate. ${ }^{50}$ In spite of the reaction types, needle-like crystals were not obtained as found with the POB whiskers. The obtained PPTE crystals were thin plate-like crystals, and polymer chains aligned perpendicular to the plane of the platelike crystal. Copolymerizations of ABA, terephthalic acid and 1,4-diacetoxybenzene were investigated. ${ }^{51}$ Copolyesters had been prepared with a systematic variation of the molar ratio in a liquid inert reaction medium at $400^{\circ} \mathrm{C}$. All copolyesters proved to be highly crystalline regardless of the molar composition. All these copolyesters are crystalline powders consisting of particles of irregular shape. Polymerization of silylated ABA with silylated terephthalic acid and 1,4diacetoxybenzene yielded copolyesters with a potatochip morphology. Polyesters based on $4,4^{\prime}$-biphenyldiol and biphenyl-4,4'-dicarboxylic acid were also examined by the polymerization of 4,4'-diacetoxybiphenyl and biphenyl-4,4'-dicarboxylic acid in Marlotherm-S. ${ }^{52}$ Polycondensations at $400{ }^{\circ} \mathrm{C}$ gave high molecular weight polymers, but true needle-like whiskers were never formed. Self-condensation type polyesters such as $\mathrm{POB}, \mathrm{PON}$ and $\mathrm{POBP}$ afford the whiskers as mentioned, but AA-BB type polyesters did not give the whiskers. This may be attributed to the structural irregularity of the oligomer end-groups leading to the different packing manner of the molecular chains or the difference in the ester group direc- tion resulting in the generation of the polarity along the molecular chain, but there still remainds unclear.

The whiskers of aromatic polymers besides polyester were also obtained by the reaction-induced crystallization of oligomers during solution polymerization. The whiskers of poly( $p$-mercaprobenzoyl) (PMB) were prepared by the polymerization of Sacetyl-4-mercaptobenzoic acid (AMBA) in liquid paraffin at $300^{\circ} \mathrm{C}$ and a concentration of $1 \%$ with no stirring. ${ }^{53,54} \mathrm{PMB}$ is an intractable aromatic polythioester. In this case, higher polymerization temperature over $320^{\circ} \mathrm{C}$ resulted in the thermal decomposition of PMB. Further, liquid paraffin was the only solvent good to form the whiskers. The PMB whiskers had nearly uniform width $0.3-0.5 \mu \mathrm{m}$ and length $5-8 \mu \mathrm{m}$, and they showed radial growth from the center part. This whisker had single crystal nature and the polymer chains aligned along the long axis of the whisker. PMB exhibited a reversible solid-solid transition at around $328^{\circ} \mathrm{C}^{55}$ and the transition temperature and enthalpy of the PMB whiskers were higher and larger than those of crystals with other morphologies.

4-Aminobenzaldehyde was polymerized at $200{ }^{\circ} \mathrm{C}$ in liquid paraffin to give polyazomethine ${ }^{56}$ Polymerization proceeds with eliminating water and the crystals were formed by the crystallization of oligomers. The obtained crystals exhibited cone-shape morphology, and the average length was $0.5-0.6 \mu \mathrm{m}$ and the average width was $0.1 \mu \mathrm{m}$. These crystals possessed high crystallinity measured by wide-angle X-ray diffraction experiment. Needle-like poly(azomethine) crystals were prepared by the polycondensation of 1,4-phenylenediamine and terephthalaldehyde in liquid paraffin at $180^{\circ} \mathrm{C} .{ }^{57}$ The morphology was susceptible to the polymerization concentration and the most preferable concentration for the preparation of uniform needle-like crystals was $2.0 \times 10^{-2} \mathrm{~mol} \mathrm{~L}^{-1}$. The average length and width of the crystals were 7.7 and $0.6 \mu \mathrm{m}$, respectively. These crystals possessed high crystallinity and the polymer chains aligned along the long axis of the needle-like crystal. The trace of the stacking lamellar structure was still observed in this needle-like crystals prepared for $6 \mathrm{~h}$. The solid-state polymerization did not occur effectively in the poly(azomethine) crystals comparing with the other whiskers. The morphology control of aromatic polyimides was examined by means of the reaction-induced phase separation. First trial was done to poly ( $p$-phenylene pyromelliteimide) (PPPI). PPPI possess a very straight and rigid-rod structure and high-performance of PPPI has been expected for a long time. Aromatic polyimides are usually neither infusible nor soluble due to their rigidity, and they are often prepared by the two-step synthesis including the synthesis of the soluble poly(amic acid) precursor 
and the following imidization. The preparation of oriented polyimide films and fibers from poly(amic acid) precursors have been numerously studied so far. However, the catenation of para and meta linkages of poly(amic acid) precursors and the rapid crystallization during imidization prevent from the formation of crystals and the orientation of polymer molecules. The morphology control method by using the reaction-induced phase separation of oligomers is a powerful tool to overcome this poor processability. Lozenge-shaped crystals and the spherical aggregates of plate-like crystals were obtained by the crystallization of oligomers during the solution polymerization of $p$-phenylenediamine and pyromellitic dianhydride as shown in Figure $7 c .{ }^{58}$ Polymer chains aligned along the long axis of the lozenge-shaped crystals. ${ }^{59}$ The temperatures of $10 \mathrm{wt} \%$ loss measured by thermogravimetric analysis were in the range of $680-730^{\circ} \mathrm{C}$ in $\mathrm{N}_{2}$ and these crystals exhibited the highest thermal stability in aromatic polymer materials. The morphology of other aromatic polyimides including Kapton was created by the similar procedure such as lath-like crystals and they also exhibited the excellent thermal stability. ${ }^{60}$

Poly(ester-imides) whiskers were prepared from $\mathrm{N}$ (4-carboxyphenyl)-4-acetoxyphthalimide in Marlotherm-S at $400{ }^{\circ} \mathrm{C}$ with no stirring. ${ }^{61}$ Copolymerization of $\mathrm{N}$-(4-carboxyphenyl)-4-acetoxyphthalimide with ABA were conducted over a broad range of molar composition in feed, and whiskers were obtained in all cases. Regardless of composition, the prepared whiskers exhibited the same type of orthorhombic crystal lattice and a degree of crystallinity $>85 \%$. All attempts to obtain whiskers from the isomeric monomer $N$-(4-acetoxyphenyl)trimellitic acid failed, even when copolyesters with ABA were prepared. These whiskers contained imide groups are of advantage as organic reinforcements from the viewpoint of the adhesion with the matrices.

With respect to polyamide, polycondensations of three $N$-(4'-aminobenzoyl)lactams were studied in various reaction media. ${ }^{62}$ The highest molecular weights were obtained in Marlotherm-S at $300-350{ }^{\circ} \mathrm{C}$. The pyrrolidone- and $\varepsilon$-caprolactam-based monomers yielded copolyamides containing 80-95\% p-aminobenzoyl units. Wide-angle X-ray diffraction patterns exhibited the typical reflections of semicrystalline poly( $p$-benzamide) with little influence of the reaction conditions. The obtained polyamides were the aggregates of shaving-like crystals. The morphology of poly(ester-amide) were then examined. ${ }^{63-66}$ Silylated $p$-aminobenzoic acid was acylated with $p$-acetoxybenzoyl chloride, and the resulting dimer was polymerized in an one-pot procedure at 350 or $400^{\circ} \mathrm{C}$. The polymerization of the dimers yielded shaving-like crystals. The polymers composed of the shavinglike crystals possessed a predominantly alternating sequence. Copolymerizations of $p$-aminobenzoic acid with $\mathrm{ABA}$ were conducted, and the needle-like crystals were only obtained from copoly(ester-amides) containing $90 \mathrm{~mol} \%$ p-oxybenzoyl units. Random copolymerization prevents from the crystallization of oligomers leading to the disappearance of the clear morphology as discussed later. Composites of nylon6 with the POB whiskers or these poly(ester-amide) needle-like crystals were prepared and their mechanical properties were evaluated. ${ }^{67}$ The POB whiskers were surface-treated with an alkali or an acidic solution to improve the adhesion with nylon- 6 matrix because the surface of the POB whiskers was very smooth. The surface treatment did not play an important role, and the poly(ester-amide)s were inferior to the polyester whiskers, because they were not single crystals.

Recently, interesting trials were performed to control the sequence regularity of copolymers by mean of the reaction-induced phase separation of oligomers. ${ }^{68-72}$ Preparation of the poly ( $p$-oxybenzoyl-co$p$-mercaptobenzoyl) whiskers was examined by solution polymerization in liquid paraffin at the concentration of $1.0 \%$ and $300^{\circ} \mathrm{C}$. Copolymerization of $\mathrm{ABA}$ and AMBA did not yield the whiskers. This was attributed to tendency that the copolymerization reduced the crystallizability of oligomers and induced the liquid-liquid phase separation of oligomers due to the lower freezing point. In order to induce short distance sequence regularity into the oligomers, copolymerizations of two among four monomers were conducted, which were 4-(4-acetoxybenzoyloxy)benzoic acid, S-(4-acetoxybenzoyl)-4-mercaptobenzoic acid (OS), 4-(S-acetyl-4-mercaptobenzoyloxy)benzoic acid (SO) and S-(S-acetyl-4-mercaptobenzoyl)-4-mercaptobenzoic acid. The copolymerizations of two of these monomers yielded the whiskers but for that of 4-(4-acetoxybenzoyloxy)benzoic acid and S-(S-acetyl-4-mercaptobenzoyl)-4-mercaptobenzoic acid. The short distance sequence regularity of oligomers brought about the crystallization of oligomers, leading to the formation of whiskers. The polymerizations of OS and SO afforded the whisker of poly( $p$-oxybenzoyl-alt- $p$-mercaptobenzoyl).$^{70}$ The whisker prepared from OS was $18 \mu \mathrm{m}$ in average length and $0.4 \mu \mathrm{m}$ in average width, and that from SO was slightly longer. Electron diffraction experiments revealed that these whiskers consisted of the alternating polymer chains, and the polymer chains aligned along the long axis of the whisker. The sequence regularity enhanced the crystallizability of the oligomers, and this led to the formation of whiskers. The oligomer formation rate was much higher than that of transesterification 


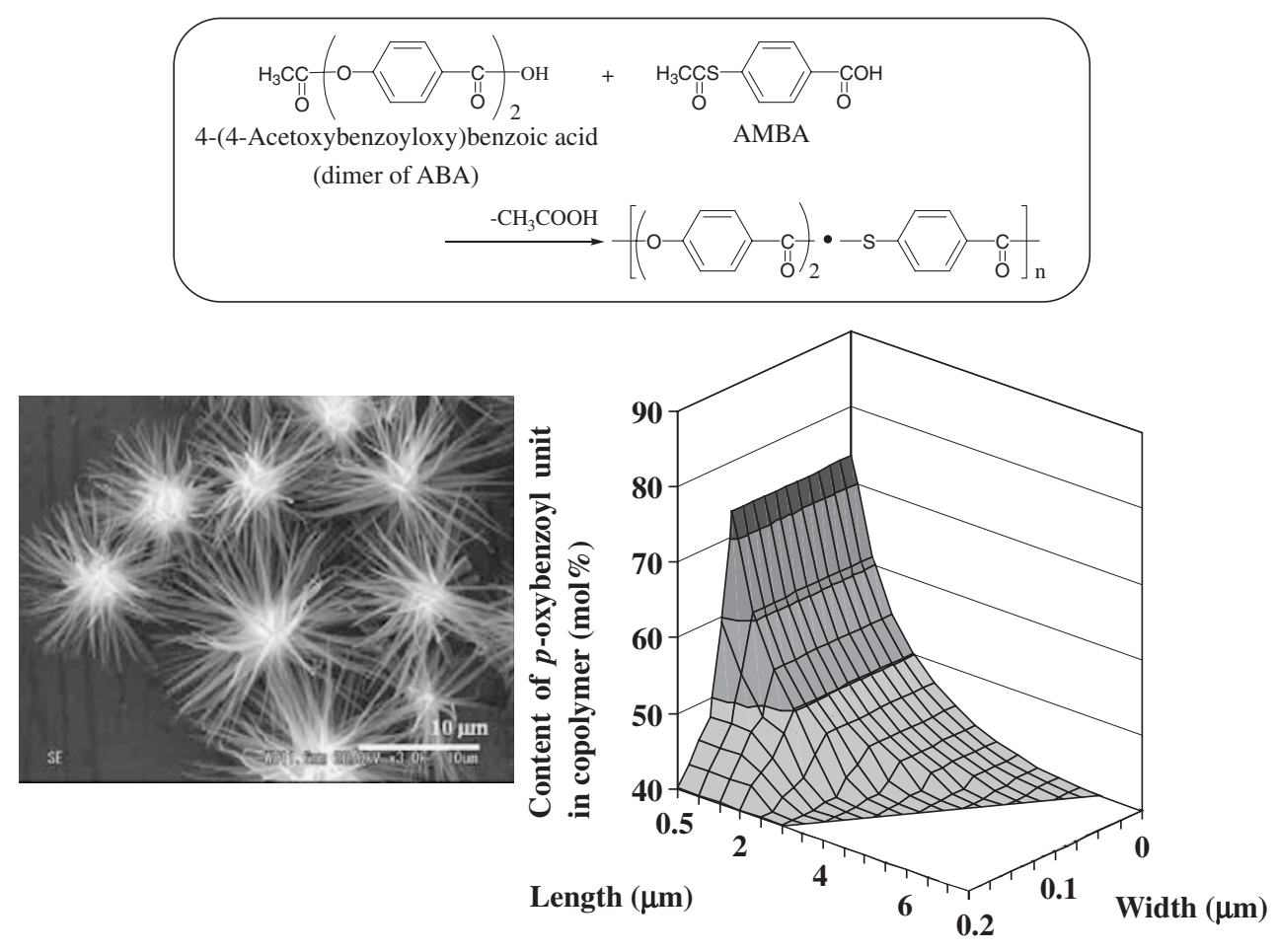

Figure 8. Polymer whiskers composed of p-oxybenzoyl units and $p$-mercaptobenzoyl units having graded composition were prepared by the polymerization of AMBA and 4-(4-acetoxybenzoyloxy)benzoic acid (dimer of ABA), and composition map in a crystal.

reaction rate, and this large difference in these two rates made the oligomer precipitate with maintaining the alternating sequence. Further polymerization occurred in the crystals, and the whiskers having the alternating sequence were finally completed. Polymer whiskers composed of $p$-oxybenzoyl units and $p$-mercaptobenzoyl units having graded composition were prepared by the polymerization of AMBA and 4-(4acetoxybenzoyloxy)benzoic acid (dimer of $\mathrm{ABA}$ ) or 4-[4-(4-acetoxybenzoyloxy)benzoyloxy]benzoic acid (trimer of $\mathrm{ABA}$ ). Polymerizations were carried out in liquid paraffin at $300{ }^{\circ} \mathrm{C}$. The polymerization concentration was $1.0 \%$ and the molar ratio of $p$-oxybenzoyl units in feed was 50\%. Polymerization of AMBA and dimer yielded copolymer whiskers and they were $15 \mu \mathrm{m}$ in average length and $0.4 \mu \mathrm{m}$ in average width. This whisker possessed a graded composition from $p$ oxybenzoyl units to $p$-mercaptobenzoyl units along the both directions of the length and the width as shown in Figure 8. The oligomers rich in $p$-oxybenzoyl unit sequences were preferentially precipitated in the early stage of polymerization, and afterward the oligomers poor in $p$-oxybenzoyl units were precipitated to form the whiskers leading to a graded composition. Polymerization of AMBA and trimer yielded copolymer whiskers with a larger gradient composition. Polymer whiskers based on $p$-mercaptobenzoyl and $p$ oxybenzoyl blocks were prepared by the polymerization of AMBA and the following addition of ABA. ${ }^{72}$ The polymerization of AMBA was firstly carried out in liquid paraffin at $300^{\circ} \mathrm{C}$ for $3 \mathrm{~h}$ to yield the PMB whisker, and then ABA was added stepwise at $3 \mathrm{~h}$ intervals into the solution. The length of the whisker increased with the addition from $20.1 \mu \mathrm{m}$ to $26.7 \mu \mathrm{m}$ after third ABA addition. Microscopic IR analysis and selected area electron diffraction measurements revealed that the molecular chains aligned along the long axis of the whiskers, and the center and tip parts were comprised of PMB crystal and POB crystal, respectively.

Wholly aromatic polyesters containing a heterocyclic moiety in repeating unit were polymerized at $>350^{\circ} \mathrm{C}$ in an inert liquid reaction medium according to this morphology control method, such as 6-acetoxythioxanthone-2-carboxylic acid, ${ }^{73}$ and 2-(4'-acetoxyphenyl)benzoxazole-5-carboxylic acid ${ }^{74}$ and 2-(4-carboxyphenyl)-5-acetoxybenzoxazole. ${ }^{75}$ Insoluble and infusible, highly crystalline polyesters were obtained but they did not form needle-like crystals. Poly[2,2'( $p$-phenylene)-5,5'-bibenzimidazole] were prepared from 3,3'-diaminobenzidine and diphenyl terephthalate in an inert aromatic solvent at $320^{\circ} \mathrm{C}$ and the bundle-like aggregates of nanofibers were obtained. The average diameter of nanofibers was $52 \mathrm{~nm} .{ }^{76}$

\section{Reaction-induced Liquid-Liquid Phase Separation}

Reaction-induced liquid-liquid phase separation during solution polymerization can be used to prepare microspheres of intractable aromatic polymers. Polymerizations of $(E)$-4-acetoxycinnamic acid were car- 

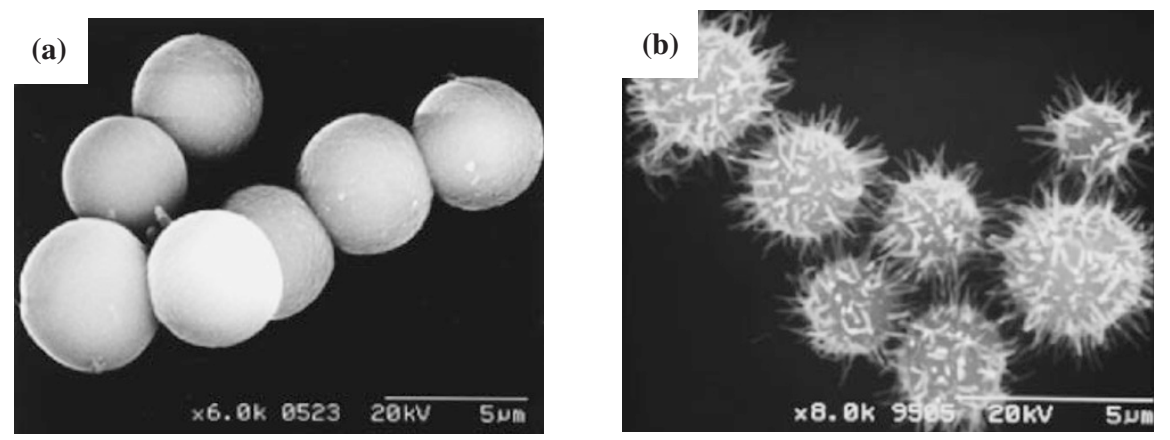

Figure 9. Morphology of (a) POC microspheres and (b) POB microspheres having needle-like crystals on surface.

ried out under various conditions. ${ }^{77}$ Polymerization in liquid paraffin yielded the microspheres of poly(p-oxycinnamoyl) (POC) having a smooth surface at $270-330^{\circ} \mathrm{C}$. The average diameter was $4.6 \mu \mathrm{m}$, as shown in Figure 9a. When the polymerization was carried out at $310^{\circ} \mathrm{C}$ in Therm S 800 and $300^{\circ} \mathrm{C}$ in Therm S 900 (a mixture of hydrogenated terphenyl, Nippon Steel Chemical Co. Ltd.), the microspheres were also obtained, of which the average diameter was 3.9 and $3.3 \mu \mathrm{m}$, respectively. The plate-like crystals were formed under these temperatures, of which thickness was $c a$. $0.1 \mu \mathrm{m}$. The formation of the microspheres was highly related to the miscibility between the oligomers and the solvents. The average diameter of the microspheres increased with the decrease of the miscibility, and this tendency could be accounted for by the interfacial tension between two immiscible liquid phases. The microspheres were formed through the formation of the microdroplets via the liquidliquid phase separation of the oligomers. The microdroplets grew with not only the consecutive supply of dense phase but also the coalescence of microdroplets. Solidification of the microdroplets occurred with maintaining spherical morphology due to the further polymerization in them, resulting in the stabilization of the surface. The diameter of the POC microspheres could be controlled by the self-seeding method with the addition of coalescence inhibiters such as $n$-octadecyloxybiphenyl. ${ }^{78,79}$ The diameter was tunable from $600 \mathrm{~nm}$ to $4 \mu \mathrm{m}$. The stirring effect on the morphology of POC was investigated and the morphology was drastically changed from spheres to rod-like crystals having a twisted structure. ${ }^{80}$ This result provides a new morphology control procedure by hydrodynamically induced crystallization.

The reaction-induced liquid-liquid phase separation also applied to the POB. The polymerization of ABA in perfluoropolyether yielded the POB microspheres due to the lower miscibility between the oligomer and the solvent. ${ }^{81}$ The polymerization in low molecular weight perfluoropolyether yielded the POB whiskers via crystallization of oligomers. The molecular weight of the perfluoropolyether strongly influenced the miscibility of oligomers and this brought about the morphological change.

The POB microspheres having unique morphology were prepared by the copolymerization. ${ }^{82,83}$ The polymerization of $\mathrm{ABA}$ and 3,5-diacetoxybenzoic acid (DABA) at a molar ratio of DABA in the feed of $0.05-0.20$ yielded the microspheres having needlelike crystals on the surface as shown in Figure $9 \mathrm{~b}$. The diameter of the microspheres was in the range of 3.4-1.6 $\mu \mathrm{m}$ and the length of the needle-like crystals was $3.2-0.3 \mu \mathrm{m}$. DABA acted as a liquid-liquid phase separation inducer and the liquid-liquid phase separation of co-oligomers comprising $p$-oxybenzoyl units and 3,5-dioxybenzoyl units was induced in the beginning of polymerization to form the core microspheres. Then the phase separation mode was changed to the crystallization of the homo-oligomers of the $p$ oxybenzoyl unit and they were crystallized as needlelike crystals on the surface of microspheres already precipitated. The microspheres having needle-like crystals were prepared by the combination of liquidliquid phase separation and the crystallization of oligomers during solution polymerization. The obtained microspheres having needle-like crystals possessed very high crystallinity. The morphology of POB is also controllable by the effect of oligomer end-groups. ${ }^{84}$ When the solution polymerizations of $p$-acyloxybenzoic acids having longer acyl groups were carried out, such as $p$-hexanoyloxybenzoic acid, $p$-octanoyloxybenzoic acid and p-decanoyloxybenzoic acid, the POB whiskers were afforded. On the other hand, the polymerization of $p$-perfluorooctanoyloxybenzoic acid yielded microspheres having fibrillated surface. Perfluorooctanoyl groups of oligomers induced the liquid-liquid phase separation of oligomers.

The microspheres of various aromatic polyimides were successfully prepared by the polymerization of diamines and dianhydrides in poor solvents..$^{58,59,85}$ The average diameter of polyimides was $0.4-1.0 \mu \mathrm{m}$ with the coefficient of variation of $34-41 \%$ as shown in Figure 7d. 
Aromatic polyimide particles have been numerously produced by the phase separation induced by imidization reaction. A solution of poly(amic acid) prepared from 4,4'-diaminodiphenyl ether and pyromellitic dianhydride in $N, N$-dimethylacetamide was added to a toluene solution containing pyridine, acetic anhydride and $\mathrm{LiCl}$ to prepare the polyimide particles. ${ }^{86}$ After filtering and drying, the polymer was suspended in acetic anhydride and refluxed overnight to undergo the complete imidization. Several kinds of highly crystalline polyimide particles were obtained by heating poly(amic acid) solutions at $180^{\circ} \mathrm{C}$ as the result of thermal imidization of poly(amic acid)s in $\mathrm{N}$-methyl2-pyrrolidone. ${ }^{87,88}$ The morphology of the particles was a sheaf or coral that was similar to spherulites of the polymer and they were found to be highly crystalline particles. The size of the particles was in the range from $1 \mu \mathrm{m}$ to $10 \mu \mathrm{m}$. Electron diffraction patterns indicated that the molecular axis of the polyimide lied perpendicular to the surface of the sheaf for the particle. These particles started to thermally decomposition from about $500^{\circ} \mathrm{C}$ and almost finished being carbonized until $1000{ }^{\circ} \mathrm{C}$ in a yield of $50 \%$. The morphologies of obtained carbon particles were unique like a whisker or coral which had the particle size from $1 \mu \mathrm{m}$ to $5 \mu \mathrm{m}$, and such particles hardly changed at all from the morphology of precursor in spite of extreme decomposing and carbonizing processed. ${ }^{89-92}$ By the treatment at $2800^{\circ} \mathrm{C}$, carbon particles from PPPI were found to be almost graphitized. The structure of particles like whiskers was made up by stacking of graphite layers, and those layers were turned and closed in a loop at the end of each particle. Nanoparticles and nanosheets of a high-performance aromatic polyimides were also synthesized via a simple monomer adsorption/polycondensation process inside the pores of specially selected mesoporous silica monoliths. ${ }^{93}$ The shape of the polyimide nanostructures was determined by the morphology of the pores of the templates.

Other typical example for the morphology control by the precipitation polymerization is the synthesis of poly(ether ketone)s (PEK). It is well known that many synthetic routes of PEK have been developed. ${ }^{94}$ Among them, the polymerization by Friedel-Crafts acylation reaction of aromatic diacid chlorides and aromatic ethers with aluminum chlorides is well known as the precipitation polycondensation, and the polymer/catalyst complex is precipitated in the form of the swollen particles. After completion of the reaction, the precipitates are isolated from the reaction solution, washed and dried to obtain polymer particles. PEK particles were prepared from 1,4- and 1,3-bis(4phenoxybenzoyl)benzenes with isophthaloyl chloride and terephthaloyl chloride, of which the dimensions were $0.1-0.5 \mathrm{~mm}$. All particles were made up of many smaller ones and the sizes of them were in the range of 5-10 $\mu \mathrm{m} .{ }^{95-100}$ PEK particles containing 2,6-naphthalene units ${ }^{101}$ and tert-butyl pendant groups ${ }^{102}$ were also prepared by the precipitation polymerization. Poly(ether ketone ether ketone ketone) particles were obtained by the precipitation polymerization of 1,4diphenoxybenzophenone with terephthaloyl chloride. The shape and size of these particles were strongly dependent on the reaction conditions, especially monomer concentration. The shape of the particle changed from elliptical to spherical one with the decrease of the concentration and the size of the particles decreased with it from 0.7 to $0.1 \mathrm{~mm}$. For low monomer concentration, highly ordered needle-like products were also formed with the spherical particles. The needlelike products were $150-250 \mu \mathrm{m}$ in length and $1-5 \mu \mathrm{m}$ in width. ${ }^{103}$ PEKs having pendant carboxyl groups have been obtained by copolycondensation of 4,4'-diphenoxybenzophenone with a mixture of terephthaloyl chloride (TC) and trimellitic anhydride acid chloride (TAAC) in the presence of aluminum chloride. ${ }^{104,105}$ Besides globular particles of polymer, small quantities of needle-like crystals were observed when the molar ratio of TAAC/TC was less than 1 . The needle-like crystals were $150-250 \mu \mathrm{m}$ long and $1-5 \mu \mathrm{m}$ wide. However, X-ray microdiffraction result had revealed that the needle-like material consisted of a cyclic compound containing ten phenylene units, i.e., the crystals are of a $[2+2]$ macrocyclic dimer.

\section{EPITAXIAL POLYMERIZATION}

In order to control morphology of aromatic polymers, polymerizations on the substrates have been studied as called epitaxial polymerization. Morphology and molecular chain orientation are controlled during polymerization with the guidance of the surface structure of the substrates. This polymerization method had been mainly applied to conjugated polymers such as polyacetylene, ${ }^{106}$ polypyrrole, ${ }^{107}$ poly$(p \text {-xylylene })^{108}$ and so on, but some of aromatic polymers were prepared by this method.

With respect to $\mathrm{POB}$, epitaxial polymerizations of $\mathrm{ABA}$ were performed onto solid crystal substrates immersed in solution. ${ }^{109-111}$ The morphology of the POB films depended on the polymerization conditions and crystal structure of the substrate. On single-crystal mica and $\mathrm{KBr}$ substrates, $\mathrm{POB}$ films formed layer-like structures with their crystal c-axis (chain axis) parallel to the substrate surface with azimuthal orientations. On polycrystalline gold, POB film consisted of lamellae standing with the c-axis parallel to the gold surface. On the highly oriented poly(tetrafluoroethylene) (PTFE) film, ${ }^{112}$ the molecular chains of POB were 
highly oriented parallel to the PTFE chain direction on well-prepared PTFE/ $\mathrm{CaF}_{2}$ and PTFE/quartz substrates. Epitaxial polymerization of $\mathrm{ABA}$ vapors on friction-transferred PTFE substrates was carried out. ${ }^{113}$ Depending on the reaction conditions, two different morphologies were observed. At low temperatures from $180^{\circ} \mathrm{C}$ to $210^{\circ} \mathrm{C}$, highly oriented and uniform thin POB films were formed, while at higher temperatures and/or longer reaction times, small crystallites grew and oriented on top of the POB films formed initially. The POB thin films grew epitaxially with contacting the (100) POB plane to the (010) PTFE substrate surface. This epitaxy was achieved with a very good lattice mismatch of $0.4 \%$, corresponding to the difference between the bPOB and aPTFE cell parameters. Epitaxial solution polymerization of $p$-acetaminobenzoic acid on mica was performed ${ }^{114}$ and it resulted in three different morphologies of poly( $p$-benzamide), the most unique being shish kebab-type structures.

Thin film melt polymerization was developed and applied to control the morphology and chain orientation of aromatic polymers. Monomers were placed in a thin layer between glass cover slips or freshly cleaved mica sheets. The sandwiched monomers were polymerized at high temperature. After polymerization, the sandwiches were slip apart and washed with solvents to remove monomers and oligomers from polymer crystals. The morphology of POB was controlled by the polymerization of ABA in constrained thin films at temperatures between $130^{\circ} \mathrm{C}$ and $315^{\circ} \mathrm{C} .{ }^{115-117}$ Polymerization below the melting point of the ABA, $196^{\circ} \mathrm{C}$ occurred by a sublimation-recrystallization-melting process, with polymerization occurring in the melt. Bilayered lamellar crystals were found, of which the thickness was $c a .10 \mathrm{~nm}$. The crystal structure of POB was suggested the presence of either triclinic phase and orthorhombic phase, and the molecular axes were normal to the lamellae. Polymerization over $200^{\circ} \mathrm{C}$ resulted in the lamellae. The morphology of PON was also investigated by this polymerization method and lamellar single crystals were prepared like POB. ${ }^{118,119}$ This polymerization method was also applied to poly(terephthalic anhydride $)^{120}$ and POBP. ${ }^{121}$ Shearing of the material shortly after the initiation of polymerization at $200^{\circ} \mathrm{C}$ yielded poly(terephthalic anhydride) single crystal domains composed of fibrillar texture material.

\section{SHEAR-INDUCED CHAIN ORIENTATION DURING GELATION IN POLYMERIZATION}

This quite interesting technique was developed for the one-pot preparation of aramide pulps. ${ }^{122}$ Polymerization of terephthaloyl chloride with $p$-phenylene- diamine was carried out in $N, N$-dimethylacetamide in the presence of $\mathrm{LiCl}$ and pyridine under vigorous stirring. The reaction mixture was changed to the gel phase immediately due to not only the reduction of miscibility of oligomers by the increase of molecular weight but also the formation of hydrogen bonding between oligomers. Then, the stirring was stopped and the polymerization was continued with no stirring. In the gel phase, the mobility of the oligomer chains were reduced and the orientation caused by the stirring was maintained. The polymerization proceeded simultaneously in the gel phase with the molecular chain packing by lateral movement of the oligomers due to the collapse of solvent bridges. Finally welloriented poly ( $p$-benzamide) short fibers were obtained. This procedure was applied to the preparation of polyimide from 1,4-phenylene diamine and 2,5diethoxycarbonyl-1,4-benzenedicarbonyl chloride. ${ }^{123}$ The strong shear stress was applied to the gel and the uni-axial orientation of the polyamide precursor molecular chains was induced along the shear direction in the gel rather than the planar mode, and ultimately the PPPI molecular chains were welloriented.

\section{TEMPLATE-BASED POLYMERIZATION}

In recent years, electrically conducting and intrinsically colored polymers are widely used in diverse applications. ${ }^{124}$ Researches into molecular wire have developed largely since the discovery of carbon nanotubes. Conducting polymers also hold promise as advanced materials in this area due to their long conjugated length and metal-like conductive property. Template-based polymerization characteristic of synthesizing the desired materials within the pores serving as template is a very useful tool to create various shapes of polymeric materials. ${ }^{125,126}$ Many unique materials have been prepared such as nanotubes, nanoribbons, nanobelts and so on. Tubes, fibers or filaments of polypyrrole, ${ }^{127-130}$ poly(o-phenylenediamine), ${ }^{115,131,132}$ polyaniline, ${ }^{130,133,134}$ poly(3-methylthiophene), ${ }^{135}$ poly(diphenylamine) ${ }^{136}$ and many conducting polymers have been prepared with a template-based method. Template-based method has been also applied for the morphology control of high-performance aromatic polymers. Nucleophilic ring-opening polymerization of macrocyclic aromatic ethers and thioethers was performed in melt phase within the cylindrical pores of an anodic-alumina membrane, followed by dissolution of the template. ${ }^{137}$ This polymerization enabled replication of the membrane's internal pore structure and afforded high-performance aromatic polymers with well-defined fibrillar or tubular morphologies. 


\section{OTHER METHODS INCLUDING SUSPENSION POLYCONDENSATION, SOLID-STATE POLYCONDENSATION AND LIQUID-LIQUID INTERFACIAL PRECIPITATION}

Suspension polycondensation had been applied to prepare the polymer spheres. Spherical poly(benzimidazole-2,5-diyl) beads were successfully prepared from 3,4-diaminobenzoic acid in liquid paraffin containing suspension stabilizer and polyphosphoric acids. ${ }^{138}$ Monomers were polycondensed to form polymers in the dispersed droplets and polymer beads were formed in the suspension. A series of surfaceactive agents and various low molecular weight polymers were tested for potential use in a high-temperature suspension polymerization. Polymeric dispersants proved most effective. The obtained particles were $106 \mu \mathrm{m}$ in average diameter.

Solid-state polymerizations in monomer crystals are often used for the preparation of polymer single crystals as mentioned ${ }^{2-6}$ and many progress is found in these days. ${ }^{139}$ This method is often used to control the stereoregularity and to prepare the crystals of addition reaction type polymers. Polycondensation reaction proceeds with eliminating by-produced molecules and therefore it is quite difficult to keep the crystal structure of monomers during polymerization. Hence, only a few studies were reported. p-Aminobenzoyl chloride hydrochloride as needle-like crystals was polymerized in solid state at high temperature and in suspension at low temperature in inert solvents with an acid acceptors. ${ }^{140}$ The polymerization proceeded with maintaining the morphology of monomers to give needle-like crystals of poly( $p$-benzamide). Molecular chains were oriented perpendicular to the long axis of needle-like crystals.

In recent years, single crystal C60 fullerene nanowhiskers $^{141-144}$ and nanotubes ${ }^{145}$ were synthesized and this success has been receiving attention for the creation of novel nano-devices. Single crystal C60 fullerene nanowhiskers were synthesized by a method of liquid-liquid interfacial precipitation using a system of C60-saturated m-xylene and iso-propyl alcohol. Photo-assisted growth of C60 nanowhiskers by the liquid-liquid interfacial precipitation method was demonstrated with various wavelengths of UV-visible light. ${ }^{146,147}$ The growth rate of C60 fullerene nanowhiskers was significantly promoted by the light illumination with only wavelengths between 600 and $625 \mathrm{~nm}$. The maximum of their lengths exceeds $1 \mathrm{~mm}$ where the diameter is $c a .250 \mathrm{~nm}$. The C60 nanowhiskers with a diameter of submicrons were found to be single crystal and composed of thin slabs with a thickness of $c a .10 \mathrm{~nm}$. The $\mathrm{C} 60$ nanowhiskers are assumed to be polymerized via the [2+2] cycloaddition in the close-packed [110]c direction.

C60 fullerene nanotubes were also fabricated by the modification of liquid-liquid interfacial precipitation using pyridine as solvent. Fibrous solids were precipitated with the length larger than several millimeters and the diameters ranging from submicrons to $1 \mu \mathrm{m}$. Tubular morphology was usually observed for the whiskers with the diameters $>200 \mathrm{~nm}$.

\section{CONCLUDING REMARKS}

Many attractive methods have been developed to control the morphology of aromatic polymers as reviewed, including reaction-induced phase separation of oligomers, epitaxial polymerization, shear-induced chain orientation during gelation, template-based polymerization and so on. Property and function of the materials are governed by not only the morphology but also the molecular chain orientation. Some of these can control these two parameters simultaneously. In recent years, it is required that the size of the device is smaller and function is more complicated. Nano-scale architecture technology is of great importance to meet these demands, and hence the morphology control method becomes more important. With respect to the materials, numerous aromatic polymers had been synthesized, but many of them were given up to use due to their poor processability. These morphology control methods during polymerization do not prevent from the intractability of polymers and the new materials comprised of rigid-rod polymers will be able to create and play an important role in times to come. Ultimate goal of the morphology control is the embodiment of the nature system in a flask, that is, the control of the materials from primary structures including molecular weight, its distribution, composition, sequence regularity, stereoregularity, etc. to super structures including morphology, molecular chain orientation, crystal structure, size, etc. In order to go deep into the precision polycondensation field, the reaction-induced crystallization of oligomers will be a bright torch for cutting a path to the threedimensional structure architecture. Explorations have already been launched toward the three-dimensional precision structure control.

\section{REFERENCES}

1. I. M. Ward, "Developments in Oriented Polymer-2," Elsevier Applied Science, London, New York, 1987.

2. E. H. Andrew and G. E. Martin, J. Mater. Sci., 8, 1315 (1973).

3. Y. R. Patell and J. M. Schultz, J. Macromol. Sci., Part B: Phys., 7, 445 (1973). 
4. M. Iguchi, H. Nakanishi, and M. Hasegawa, J. Polym. Sci., Al, 6, 1055 (1968).

5. H. Nakanishi, Y. Suzuki, F. Suzuki, and M. Hasegawa, J. Polym. Sci., A1, 7, 753 (1969).

6. G. Wagner, Makromol. Chem., 154, 35 (1972).

7. D. Bloor, L. Koski, G. C. Steevns, F. H. Preston, and D. J. Ando, J. Mater. Sci., 10, 1678 (1975).

8. M. Iguchi, Br. Polym. J., 5, 195 (1973).

9. M. Iguchi, I. Murase, and K. Watanabe, Br. Polym. J., 6, 61 (1974).

10. M. Iguchi and I. Murase, Makromol. Chem., 176, 2113 (1975).

11. M. Iguchi, T. Suehiro, T. Watanabe, Y. Nishi, and M. Uryu, J. Mater. Sci., 17, 1632 (1982).

12. M. Shimomura, Y. Maeda, and Y. Tanabe, J. Mater. Sci., 24, 2245 (1989).

13. For example: P. E. Cassidy, "Thermally Stable Polymers, Syntheses and Properties," Marcel Dekker, New York, 1980.

14. R. B. Richards, Trans. Faraday Soc., 41, 10 (1946).

15. P. J. Flory, L. Mandelkern, and H. K. Hall, J. Am. Chem. Soc., 73, 2532 (1951).

16. J. Economy and R. S. Storm, Macromolecular Monographs, 3, 45 (1977).

17. J. Tsay, W. Volksen, and J. Economy, Polym. Prepr. (Am. Chem. Soc., Div. Polym. Chem.), 23, 266 (1982).

18. J. Economy, W. Volksen, and R. H. Geiss, Mol. Cryst. Liq. Cryst., 105, 289 (1984).

19. G. Lieser, G. Schwarz, and H. R. Kricheldorf, J. Polym. Sci., Part B: Polym. Phys., 21, 1599 (1983).

20. S. Endo, K. Kimura, and Y. Kato, U.S. Patent 4,673,724 (1987).

21. Y. Kato, S. Endo, K. Kimura, Y. Yamashita, H. Tsugita, and K. Monobe, Kobunshi Ronbunshu, 44, 35 (1987).

22. Y. Yamashita, Y. Kato, S. Endo, K. Kimura, H. Tsugita, and K. Monobe, Kobunshi Ronbunshu, 44, 41 (1987).

23. Y. Kato, Y. Yamashita, K. Kimura, S. Endo, and K. Kajisaki, Kobunshi Ronbunshu, 45, 973 (1988).

24. Y. Yamashita, Y. Kato, S. Endo, and K. Kimura, Makromol. Chem., Rapid Commun., 9, 687 (1988).

25. Y. Kato, Y. Yamashita, K. Kimura, S. Endo, and T. Ohta, Kobunshi Ronbunshu, 47, 583 (1990).

26. Y. Yamashita and K. Kimura, in "Polymeric Materials Encyclopedia," CRC Press, Boca Raton, 1996, pp 87078713.

27. J. Liu and P. H. Geil, Polymer, 34, 1366 (1993).

28. P. Iannelli and D. Y. Yoon, J. Polym. Sci., Part B: Polym. Phys., 33, 977 (1995).

29. N. V. Lukasheva, A. Sariban, T. Thomas, and J. Brickmann, Macromolecules, 27, 4726 (1994).

30. R. Geiss, W. Volksen, J. Tsay, and J. Economy, J. Polym. Sci., Polym. Lett. Ed., 22, 433 (1984).

31. B. L. Yuan, F. Rybnikar, P. Saha, and P. H. Geil, J. Polym. Sci., Part B: Polym. Phys., 37, 3532 (1999).

32. H. R. Kricheldorf, F. Ruhser, G. Schwarz, and T. Adebahr, Makromol. Chem., 192, 2371 (1991).

33. C. Taesler, J. Petermann, H. R. Kricheldorf, and G. Schwarz, Makromol. Chem., 192, 2255 (1991).

34. H. R. Kricheldorf and G. Schwarz, Polymer, 31, 481
(1990).

35. H. R. Kricheldorf, G. Schwarz, and F. Ruhser, Macromolecules, 24, 3584 (1991).

36. W. K. Burton, N. Cabrera, and F. C. Frank, Philos. Trans. R. Soc. London, Ser. A, 243, 299 (1950).

37. F. C. Frank, Adv. Phys., 1, 91 (1952).

38. K. Kimura, S. Endo, Y. Kato, and Y. Yamashita, Polymer, 35, 123 (1994).

39. K. Kimura, A. K. Sarker, H. Ohmori, and Y. Yamashita, J. Appl. Polym. Sci., 87, 1129 (2003).

40. A. K. Sarker, K. Kimura, S. Uchida, and Y. Yamashita, High Perform. Polym., 14, 155 (2002).

41. A. K. Sarker, K. Kimura, and Y. Yamashita, Polym. J., 34, 426 (2002).

42. K. Kimura, S. Yamazaki, Y. Matsuoka, and Y. Yamashita, Polym. J., 37, 906 (2005).

43. A. Muehlebach, J. Lyerla, and J. Economy, Macromolecules, 22, 3741 (1989).

44. K. Kimura, S. Endo, Y. Kato, and Y. Yamashita, Polymer, 34, 1054 (1993).

45. G. Schwarz and H. R. Kricheldorf, Macromolecules, 24, 2829 (1991).

46. H. R. Kricheldorf and T. Adebahr, High Perform. Polym., 6, 109 (1994).

47. A. K. Sarker, K. Kimura, and Y. Yamashita, J. Appl. Polym. Sci., 88, 1320 (2003).

48. K. Kimura, S. Endo, Y. Kato, T. Inaba, and Y. Yamashita, Macromolecules, 28, 255 (1995).

49. G. Schwarz and H. R. Kricheldorf, Macromolecules, 28, 3911 (1995).

50. K. Kimura, S. Endo, Y. Kato, and Y. Yamashita, High Perform. Polym., 6, 83 (1994).

51. G. Schwarz, U. Zemann, and H. R. Kricheldorf, High Perform. Polym., 9, 61 (1997).

52. H. R. Kricheldorf, O. Struve, and G. Schwarz, Polymer, 37, 4311 (1996).

53. K. Kimura and Y. Yamashita, Polymer, 35, 3311 (1994).

54. K. Kimura, D. Nakajima, K. Kobashi, S. Kohama, T. Uchida, and Y. Yamashita, Polym. J., 37, 471 (2005).

55. H. R. Kricheldorf and A. Conradi, Macromolecules, 22, 14 (1989).

56. K. Kimura, J.-H. Zhuang, M. Kida, Y. Yamashita, and Y. Sakaguchi, Polym. J., 35, 455 (2003).

57. K. Kimura, J.-H. Zhuang, K. Shirabe, and Y. Yamashita, Polymer, 44, 4761 (2003).

58. K. Kimura, J.-H. Zhuang, K. Wakabayashi, and Y. Yamashita, Macromolecules, 36, 6292 (2003).

59. K. Wakabayashi, S. Yamazaki, and K. Kimura, Polym. Prepr., Jpn., 54, 599 (2005).

60. K. Kimura, Polym. Prepr., Jpn., 55, 76 (2006).

61. H. R. Kricheldorf, G. Schwarz, T. Adebahr, and D. J. Wilson, Macromolecules, 26, 6622 (1993).

62. H. R. Kricheldorf and G. Loehden, Macromolecules, 27, 7880 (1994).

63. H. R. Kricheldorf, G. Schwarz, T. Adebahr, and S. Thomsen, Polym. Prepr. (Am. Chem. Soc., Div. Polym. Chem.), 34, 768 (1993).

64. H. R. Kricheldorf and G. Loehden, Polym. Prepr. (Am. Chem. Soc., Div. Polym. Chem.), 36, 725 (1995). 
65. H. R. Kricheldorf and G. Loehden, Polymer, 36, 1697 (1995).

66. H. R. Kricheldorf, G. Loehden, and D. J. Wilson, Macromolecules, 27, 1669 (1994).

67. H. R. Kricheldorf, T. Adebahr, and L. Wahlen, J. Polym. Sci., Part A: Polym. Chem., 32, 1601 (1994).

68. K. Kobashi, K. Kimura, and Y. Yamashita, Polymer, 45, 7099 (2004).

69. K. Kimura, D. Nakajima, K. Kobashi, Y. Yamashita, F. Yokoyama, T. Uchida, and Y. Sakaguchi, Polym. Adv. Technol., 11, 747 (2000).

70. K. Kobashi, K. Kimura, Y. Yamashita, T. Uchida, and Y. Sakaguchi, Macromolecules, 36, 4268 (2003).

71. K. Kobashi, K. Kimura, and Y. Yamashita, Macromolecules, 37, 7570 (2004).

72. K. Kobashi, K. Kimura, T. Uchida, Y. Yamashita, and K. Shimamura, Polymer, 46, 2191 (2005).

73. H. R. Kricheldorf and T. Adebahr, J. Polym. Sci., Part A: Polym. Chem., 32, 159 (1994).

74. H. R. Kricheldorf and S. A. Thomsen, Macromolecules, 26, 6628 (1993).

75. H. R. Kricheldorf and S. A. Thomsen, Makromol. Chem., 194, 2063 (1993).

76. S. Kohama, J. Gong, S. Yamazaki, K. Kimura, and K. Shimamura, POLYCHAR-14, Prepr., 142 (2006).

77. K. Kimura, H. Inoue, S. Kohama, Y. Yamashita, and Y. Sakaguchi, Macromolecules, 36, 7721 (2003).

78. K. Kimura, S. Kohama, Y. Yamashita, T. Uchida, and Y. Sakaguchi, Polymer, 44, 7383 (2003).

79. Y. Hirai, S. Yamazaki, and K. Kimura, Sen'i Gakkaishi, 62, 167 (2006).

80. K. Kimura, M. Muraoka, T. Uchida, and Y. Yamashita, Polym. Prepr. (Am. Chem. Soc., Div. Polym. Chem.), 46, 696 (2005).

81. K. Kimura, H. Ohmori, T. Uchida, and Y. Yamashita, Polym. Adv. Technol., 16, 6 (2005).

82. K. Kimura, S. Kohama, S. Kondoh, Y. Yamashita, T. Uchida, T. Oohazama, and Y. Sakaguchi, Macromolecules, 37, 1463 (2004).

83. K. Kimura, S. Kohama, S. Kondoh, T. Uchida, Y. Yamashita, T. Oohazama, and Y. Sakaguchi, J. Polym. Sci., Part A: Polym. Chem., 43, 1624 (2005).

84. K. Kimura, H. Ohmori, F. Yokoyama, and Y. Yamashita, Polym. Prepr. (Am. Chem. Soc., Div. Polym. Chem.), 39, 863 (1998).

85. O. Hirai, H. Nishizawa, S. Kawaguchi, K. Fujimoto, and A. Okamura, Jpn. Kokai Tokkyo Koho 09302089 (1997).

86. A. L. Endrey, U. S. Patent 3179631 (1965).

87. Y. Nagata, Y. Oonishi, and C. Kajiyama, Kobunshi Ronbunshu, 53, 63 (1996).

88. K. Asao, H. Ohnishi, and H. Morita, Kobunshi Ronbunshu, 57, 271 (2000).

89. Y. Nagata, Y. Ohnichi, H. Hatori, M. Shiraishi, and C. Kajiyama, Kobunshi Ronbunshu, 53, 302 (1996).

90. Y. Nagata, H. Hatori, and M. Shiraishi, Tanso, 177, 70 (1997).

91. Y. Nagata and M. Hirai, Tanso, 183, 141 (1998).

92. Y. Nagata and M. Hirai, Kobunshi Ronbunshu, 55, 549 (1998).
93. G. Matthijs, T. Arne, and A. Markus, Macromolecules, 37, 4360 (2004).

94. For examples; a) P. A. Staniland, "Comprehensive Polymer Science,” Pergamon Press, Oxford, 1989, vol. 5, p. 483.

b) J. B. Rose, "High Performance Polymers: Their Origin and Development," Elsevier, New York, 1986, p. 187.

c) M. J. Mullins and E. P. Woo, J. Macromol. Sci., Rev. Macromol. Chem. Phys., 27, 313 (1986).

95. M. G. Zolotukhin, D. R. Rueda, F. J. B. Calleja, M. Bruix, and N. G. Gileva, Macromol. Rep., A32, 897 (1995).

96. M. G. Zolotukhin, D. R. Rueda, C. F. J. Balta, M. Bruix, M. E. Cagiao, A. Bulai, and N. G. Gileva, Macromol. Chem. Phys., 198, 1131 (1997).

97. M. G. Zolotukhin, D. R. Rueda, F. J. B. Calleja, M. E. Cagiao, M. Bruix, E. A. Sedova, and N. G. Gileva, Polymer, 38, 1471 (1997).

98. M. G. Zolotukhin, D. R. Rueda, M. Bruiz, M. E. Cagiao, C. F. J. Balta, A. Bulai, N. G. Gileva, and L. Van der Elst, Polymer, 38, 3441 (1997).

99. D. R. Rueda, M. G. Zolotukhin, M. E. Cagiao, F. Ania, M. Dosiere, D. Villers, and J. De Abajo, J. Macromol. Sci., Part B: Phys., 40, 709 (2001).

100. M. G. Zolotukhin, C. F. J. Balta, D. R. Rueda, and J. M. Palacios, Acta Polym., 48, 269 (1997).

101. M. G. Zolotukhin, M. Dosiere, C. Fougnies, D. Villers, N. G. Gileva, and A. A. Fatykhov, Polymer, 36, 3575 (1995).

102. M. G. Zolotukhin, J. De Abajo, J. C. Alvarez, J. G. De La Campa, and D. R. Rueda, J. Polym. Sci., Part A: Polym. Chem., 36, 1251 (1998).

103. D. R. Rueda, M. G. Zolotukhin, M. E. Cagiao, C. F. J. Balta, D. Villers, and M. Dosiere, Macromolecules, 29, 7016 (1996).

104. M. G. Zolotukhin, H. M. Colquhoun, L. G. Sestiaa, D. R. Rueda, and D. Flot, Macromolecules, 36, 4766 (2003).

105. M. G. Zolotukhin, H. M. Colquhoun, L. G. Sestiaa, D. J. Williams, D. R. Rueda, and D. Flot, Polymer, 45, 783 (2004).

106. For examples; a) Y. Yamashita, S. Nishimura, K. Shimamura, and K. Monobe, Makromol. Chem., 187, 1757 (1986).

b) S. Sakurai, K. Okoshi, J. Kumaki, and E. Yashima, Angew. Chem., Int. Ed., 45, 1245 (2006).

c) I. Moggio, M. J. Le, E. Arias-Marin, D. Issautier, A. Thierry, D. Comoretto, G. Dellepiane, and C. Cuniberti, Macromolecules, 34, 7091 (2001).

d) M. Ozaki, Y. Ikeda, and T. Arakawa, J. Polym. Sci., Polym. Lett., 21, 989 (1983).

107. D. B. Wurm, S. T. Brittain, and Y.-T. Kim, Langmuir, 12, 3756 (1996).

108. S. Isoda, Polymer, 25, 615 (1984).

109. J. Wang, A. Kaito, K. Yase, and N. Tanigaki, Polymer, 37, 3247 (1996).

110. F. Rybnikar and P. H. Geil, J. Polym. Sci., Part B: Polym. Phys., 35, 1807 (1997).

111. J. Wang, A. Kaito, S. Ohnishi, N. Tanigaki, and K. Yase, J. Macromol. Sci., Part B: Phys., 37, 1 (1998).

112. J. Wang, A. Kaito, S. Ohnishi, N. Tanigaki, and K. Yase, Macromolecules, 29, 8271 (1996). 
113. P. Damman, M. Dosiere, and J. C. Wittmann, Macromolecules, 30, 8386 (1997).

114. H. Bao, F. Rybnikar, P. Saha, J. Yang, and P. H. Geil, J. Macromol. Sci., Part B: Phys., 40, 869 (2001).

115. F. Rybnikar, J. Liu, and P. H. Geil, Macromol. Chem. Phys., 195, 81 (1994).

116. J. Liu, B.-L. Yuan, P. H. Geil, and D. L. Dorset, Polymer, 38, 6031 (1997).

117. F. Rybnikar, P. Saha, B.-L. Yuan, and P. H. Geil, J. Polym. Sci., Part B: Polym. Phys., 37, 3520 (1999).

118. J. Liu, F. Rybnikar, and P. H. Geil, J. Polym. Sci., Part B: Polym. Phys., 30, 1469 (1992).

119. F. Rybnikar, J. Liu, J. A. Myers, and P. H. Geil, Korea Polym. J., 6, 53 (1998).

120. J. Liu, T.-C. Long, P. H. Geil, and F. Rybnikar, J. Polym. Sci., Part B: Polym. Phys., 34, 2843 (1996).

121. J. Liu, F. Rybnikar, A. J. East, and P. H. Geil, J. Polym. Sci., Part B: Polym. Phys., 31, 1923 (1993).

122. H. S. Yoon, Nature, 326, 580 (1987).

123. J.-H. Zhuang, K. Kimura, C.-E. Xia, and Y. Yamashita, High Perform. Polym., 17, 35 (2005).

124. For examples; a) C. L. Curtis, Adv. Mater., 6, 688 (1994). b) A. G. MacDiamid, Synth. Met., 84, 27 (1997).

125. A. Curulli, F. Valentini, S. Orlanducci, M. L. S. Terranova, C. Paoletti, and G. Palleschi, Sens. Actuators, B, 100, 65 (2004).

126. For examples; a) C. R. Martin, Adv. Mater., 3, 457 (1991). b) Z. Cai and C. R. Martin, J. Am. Chem. Soc., 111, 4138 (1989).

c) C. R. Martin, L. S. van Dyke, Z. Cai, and W. Liang, J. Am. Chem. Soc., 112, 8976 (1990).

d) V. M. Cepak and C. R. Martin, Chem. Mater., 11, 1363 (1999).

e) R. Parthasarathy and C. R. Martin, Nature, 369, 298 (1994).

127. M. Ikegame, K. Tajima, and T. Aida, Angew. Chem., Int. Ed., 42, 2154 (2003).

128. F. Zhang, T. Nyberg, and O. Inganas, Nano Lett., 2, 1373 (2002).
129. J. Jang and H. Yoon, Chem. Commun., 6, 720 (2003).

130. Z. Wei, Z. Zhabg, and M. Wan, Langmuir, 18, 917 (2002).

131. E. Wang, S. Erkang, and D. S. Xuping, U. S. Patent 277757 (2005).

132. X. Sun, S. Dong, and E. Wang, Chem. Commun., 10, 1182 (2004).

133. G. Li, H. Peng, Y. Wang, Y. Qin, Z. Cui, and Z. Zhang, Macromol. Rapid Commun., 25, 1611 (2004).

134. A. D. Carswell, E. A. O'Rear, and B. P. Grady, J. Am. Chem. Soc., 125, 14793 (2003).

135. B. W. Maynor, S. F. Filocamo, M. W. Grinstaff, and J. Liu, PMSE Prepr., 86, 207 (2002).

136. K.-P. Lee, A. M. Showkat, A. I. Gopalan, S.-H. Kim, and S.-H. Choi, Macromolecules, 38, 364 (2005).

137. H. M. Colquhoun, M. G. Zolotukhin, L. G. Sestiaa, F. Arico, Z. Zhu, P. Hodge, A. Ben-Haida, and D. J. Williams, J. Mater. Chem., 13, 1504 (2003).

138. T. Brock and D. C. Sherrington, Polymer, 33, 1773 (1992).

139. A. Matsumoto, Prog. React. Kinet. Mech., 26, 59 (2001).

140. P. W. Morgan, Macromolecules, 10, 1381 (1977).

141. K. Ogawa, T. Kato, A. Ikegami, H. Tsuji, N. Aoki, J. P. Bird, and Y. Ochiai, J. Phys.: Conference Series, 38, 1 (2006).

142. S.-H. Lee, K. Miyazawa, and R. Maeda, Carbon, 43, 887 (2005).

143. K. Miyazawa, C. Nishimura, M. Fujino, T. Suga, and T. Yoshii, Trans. Mater. Res. Soc. Jpn., 29, 1965 (2004).

144. K. Miyazawa, Y. Kuwasaki, K. Hamamoto, S. Nagata, A. Obayashi, and M. Kuwabara, Surf. Interface Anal., 35, 117 (2003).

145. J. Minato, K. Miyazawa, and T. Suga, Sci. Technol. Adv. Mater., 6, 272 (2005).

146. K. Kobayashi, M. Tachibana, and K. Kojima, J. Cryst. Growth, 274, 617 (2005).

147. M. Tachibana, K. Kobayashi, T. Uchida, K. Kojima, M. Tanimura, and K. Miyazawa, Chem. Phys. Lett., 374, 279 (2003).

148. K. Miyazawa, Y. Kuwasaki, A. Obayashi, and M. Kuwabara, J. Mater. Res., 17, 83 (2002).

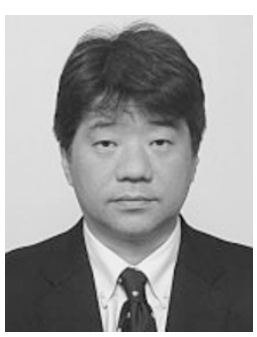

Kunio Kimura, born in 1958 (Yamaguchi, Japan), received his bachelor degree in 1981 and master degree in 1983 from Osaka University, Japan. He worked for TOYOBO Co. Ltd. from 1983 to 1995. During 1989-1991, he worked on synthesis of fluorine-containing polymers as a research associate at Southwest Texas State University with Professor Patrick E. Cassidy. He received doctorate degree of engineering from Osaka University on crystallization of aromatic polymers during solution polymerization in 1995. In 1995, he joined Faculty of Environmental Science and Technology, Okayama University, Japan as Lecturer and was promoted to associate professor in 1999 and full professor in 2003. His research interest covers morphology control of polymers by using phase separation, precision polycondensation, and synthesis of fluorine-containing aromatic polymers.

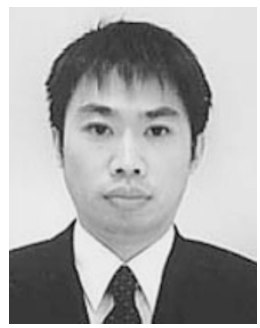

Shin-ichiro Kohama was born in Miyazaki, Japan in 1977. He received his bachelor in 1999 and master degree in 2001 from Faculty of Environmental Science and Technology, Okayama University, Japan, and also received doctorate degree of engineering on study of nonstoichiometric polycondensation through oligomer phase separation from Okayama University, Japan in 2004. He did postdoctoral research with Professor Kunio Kimura at the same department from 2004 to 2006. In 2006, he joined Graduate School of Environmental Science, Okayama University as a 21 st century COE research associate. His research interests are morphology control of aromatic polymers and highly controlled polycondensation by using phase separation of oligomers. 


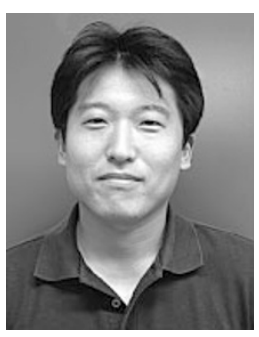

Shinichi Yamazaki was born in Ishikawa, Japan in 1972. He graduated from Faculty of Engineering, Nagoya University, Japan in 1994 and received his master degree in engineering in 1996 and doctorate degree of engineering in 1999 from also Nagoya University on study of the effects of steric hindrance and electrostatic interaction in local dynamics of polymer chain. Then he worked on crystallization of polymers as a postdoctoral researcher at Hiroshima University with Professor Masamichi Hikosaka from 1999 to 2004. In 2004, he joined Faculty of Environmental Science and Technology, Okayama University, Japan as Lecturer. His research interest covers nucleation and morphology of polymers, crystallization of polymers under flow, and polyelectrolytes solution and dynamics. 